\title{
Autophagy and Autophagy-Related Proteins in CNS Autoimmunity
}

\author{
Christian W. Keller ${ }^{1}$ and Jan D. Lünemann ${ }^{1,2 *}$ \\ 1 Institute of Experimental Immunology, Laboratory of Neuroinflammation, University of Zürich, Zürich, Switzerland, \\ ${ }^{2}$ Department of Neurology, University Hospital Zürich, Zürich, Switzerland
}

\section{OPEN ACCESS}

Edited by:

Robert Weissert,

University of Regensburg, Germany

Reviewed by:

Laura Santambrogio,

Albert Einstein College of Medicine,

USA

Craig Michael Walsh,

University of California Irvine, USA

*Correspondence:

Jan D. Lünemann

jan.luenemann@uzh.ch

Specialty section:

This article was submitted to Multiple Sclerosis and Neuroimmunology,

a section of the journal

Frontiers in Immunology

Received: 23 December 2016 Accepted: 02 February 2017

Published: 27 February 2017

Citation:

Keller CW and Lünemann JD (2017) Autophagy and Autophagy-Related Proteins in CNS Autoimmunity.

Front. Immunol. 8:165.

doi: 10.3389/fimmu.2017.00165
Autophagy comprises a heterogeneous group of cellular pathways that enables eukaryotic cells to deliver cytoplasmic constituents for lysosomal degradation, to recycle nutrients, and to survive during starvation. In addition to these primordial functions, autophagy has emerged as a key mechanism in orchestrating innate and adaptive immune responses and to shape $\mathrm{CD}^{+} \mathrm{T}$ cell immunity through delivery of peptides to major histocompatibility complex (MHC) class II-containing compartments (MIICs). Individual autophagy proteins additionally modulate expression of $\mathrm{MHC}$ class I molecules for $\mathrm{CD} 8^{+} \mathrm{T}$ cell activation. The emergence and expansion of autoreactive $\mathrm{CD}^{+}$and $\mathrm{CD}^{+} \mathrm{T}$ cells are considered to play a key role in the pathogenesis of multiple sclerosis (MS) and its animal model experimental autoimmune encephalomyelitis. Expression of the essential autophagy-related protein 5 (Atg5), which supports T lymphocyte survival and proliferation, is increased in T cells isolated from blood or brain tissues from patients with relapsing-remitting MS. Whether Atgs contribute to the activation of autoreactive $T$ cells through autophagy-mediated antigen presentation is incompletely understood. Here, we discuss the complex functions of autophagy proteins and pathways in regulating $T$ cell immunity and its potential role in the development and progression of MS.

Keywords: autophagy pathways, non-canonical autophagy, multiple sclerosis, EAE/MS, oligodendrocyte death, antigen presentation

\section{INTRODUCTION}

Organisms with subcellular compartmentalization and membrane-bound organelles face constant challenges in order to maintain metabolic integrity and homeostasis. Autophagy comprises a set of evolutionary conserved catabolic pathways that converge in the guided direction of assigned cargo to the endolysosomal system (1-3). At first, autophagy was predominantly recognized for its contribution in keeping energy homeostasis, and degradation of aberrant protein aggregates (4, 5 ) as well as mediator of development-associated forms of cell death (6). In recent years, however, autophagy's function has exceeded the originally allotted role as a mere protein degradation system alongside the proteasomal machinery. In addition to regulating cellular proteostasis and cell death, autophagy pathways are increasingly being recognized for actively participating in physiological and pathological immune responses. In doing so, autophagy pathways limit intracellular proliferation of pathogens (7), restrict secretion of proinflammatory mediators (8), and tweak $\mathrm{T}$ cell responses by orchestrating both loading and preservation of antigens on and surface-expression of antigenpresenting molecules (9-12).

Multiple sclerosis (MS) is a chronic inflammatory disease of the central nervous system (CNS), which is driven by a complex interplay of genetic, environmental, metabolic, and immunological 
factors. The strong genetic association between MS and the major histocompatibility complex (MHC) allele $\mathrm{DRB1}{ }^{\star} 1501$ suggests that $\mathrm{CD}^{+} \mathrm{T}$ cell-mediated antigen responses play a key role in its pathogenesis. This notion is supported by the presence of clonally expanded T and B cells in MS lesions and cerebrospinal fluid samples derived from MS patients (13-15). In this review, we will first illustrate the biology of distinct autophagy pathways and their function in regulating adaptive immunity in order to discuss how the autophagy machinery potentially interferes with pathogenic adaptive immune responses in MS.

\section{AUTOPHAGY}

Canonical autophagy implicates at least three distinct pathways: macroautophagy (MA), microautophagy (MI), and chaperonemediated autophagy (CMA) (16). Although all of the above mentioned pathways coalesce in the lysosome, they considerably differ (albeit showing some overlap), in their means of cargo transportation, triggering events, and regulatory factors.

\section{MACROAUTOPHAGY}

Macroautophagy, the canonical autophagy pathway sensu strictu, is evolutionary conserved from yeast to mammalian cells and characterized by highly regulated membrane reorganization processes with the subsequent de novo formation of a $0.5-1.5 \mu \mathrm{m}$ wide double-membraned vesicle termed autophagosome (17). Upon sequestering neighboring parts of the cytoplasm, the autophagosome subsequently fuses with lysosomes resulting in enzymatic cargo break down $(18,19)$. The process is partitioned in five sequential steps (1. induction/nucleation, 2. elongation, 3. closing/maturation, 4 . fusion, 5. degradation) that are orchestrated by hierarchies of autophagy-related genes/proteins (Atgs) and other essential components, in a tightly regulated enzymatic cascade $(16,20,21)$ (Figure 1). Albeit originally identified in yeast, mammalian counterparts for many Atgs have been characterized and some Atgs are so far exclusively reported in mammalian cells and lack yeast orthologs (21). Among all autophagy pathways, MA is to date the most extensively investigated one and, depending on the target constituent encompasses subentities such as macromitophagy, -pexophagy, -xenophagy, and -lipophagy (21-25).

\section{Atg Machinery and Autophagosome Formation}

De novo synthesis and maturation of the autophagosome as well as the trafficking of such vesicles to and fusion with lysosomes are distinctive features of MA in opposition to other autophagy pathways. Formation of this typifying vesicle requires approximately 5-10 min and is under the control of an ever-growing number of Atgs $(19,21,26,27)$. The finalized autophagosome is usually swiftly turned over but may reach a half-life of 10-25 min (28, 29). The key proteins that initiate and govern the formation of the autophagosome can be assembled in functionally designated groups: unc 51-like kinase (ULK) complex (1), the class III phosphatidylinositide 3-kinase (PI3K) complex (2), the Atg2/ WD repeat domain phosphoinositide-interacting protein (WIPI) complex and the Atg9 cycling system (3), the Atg12-conjugation system (4), and the microtubule-associated protein 1 light chain 3 (LC3)-conjugation system (5) $(19,21,30)$.

The autophagosome emanates from the double-membraned phagophore (also called isolation membrane), which sequesters and closes around designated parts of the cytoplasm to form the completed autophagosome. The emergence of said phagophore constitutes the induction/nucleation phase. However, the exact assembly platform and membrane source for the generation of these initial structures are still debated. Similar to the pre-autophagosomal structure that is observed adjacent to the vacuole in yeast, an autophagosome formation site, represented by dot-like accumulations of Atgs, has been identified in mammalian cells (31). Primary suspect organelles to provide membranes include specialized PI3P-enriched endoplasmic reticulum (ER) domains coined omegasomes (32). 3D electron tomography studies corroborated these results by showing that the double-membraned phagophore originates in between two protruding ER flaps. The phagophore then entwines one of the two extensions and finally buds off the ER containing the previously enfolded ER flap. This model is further supported by the fact that $>70 \%$ of autophagosomes contain ER-derived cargo $(33,34)$. Nevertheless, other membrane sources for autophagosome generation have been suggested. Among them is the outer mitochondrial membrane (35). These two opposing results might be brought together by a recent study that identified ER-mitochondria contact sites as the originating platform for the autophagosome initiation (36). The VAMP3-dependent heterotypic fusion between early endosome-derived Atg9 ${ }^{+}$ vesicles and recycling endosome-derived Atg16L $1^{+}$vesicles has also been suggested to contribute to autophagosome precursor generation (37). Additionally, ER exit sites $(38,39)$, the ER-Golgi intermediate compartment together with coat protein complex II $(40,41)$, the plasma membrane (42), and a novel compartment comprised of Atg9+ vesicles and tubules (43) were implicated in providing membrane material. It is conceivable that different subentities of MA preferentially harness distinct membrane sources. Possibly, there is a hierarchy of membrane reservoirs that sequentially may serve as alternative when other sources have been exploited. Furthermore, various tissues with specific composition of subcellular compartments may differ in their means to utilize membranes for autophagosome generation.

\section{The Atg Core Machinery}

The ULK complex is an upstream Atg-unit and, by differential phosphorylation of ULK1 (the main mammalian ortholog to yeast Atg1), a direct target of MA regulation via target of rapamycin complex 1 (TORC1) and AMP-activated protein kinase (AMPK), respectively $(44,45)$. ULK1/2 builds a stable complex with FIP200, Atg13, and Atg101 (46-48). Not composition of the complex itself but rather differential phosphorylation of its members procures promotion or inhibition of MA. In a state of MA inactivation, TORC1 restrains the process by coordinate phosphorylation of ULK1/2 and Atg13. During activation, MA-promoting phosphorylation of ULK1/2 via AMPK, ULK1/2 autophosphorylation, and ULK1/2-mediated phosphorylation of Atg13 and FIP200 occur followed by translocation of the entire 


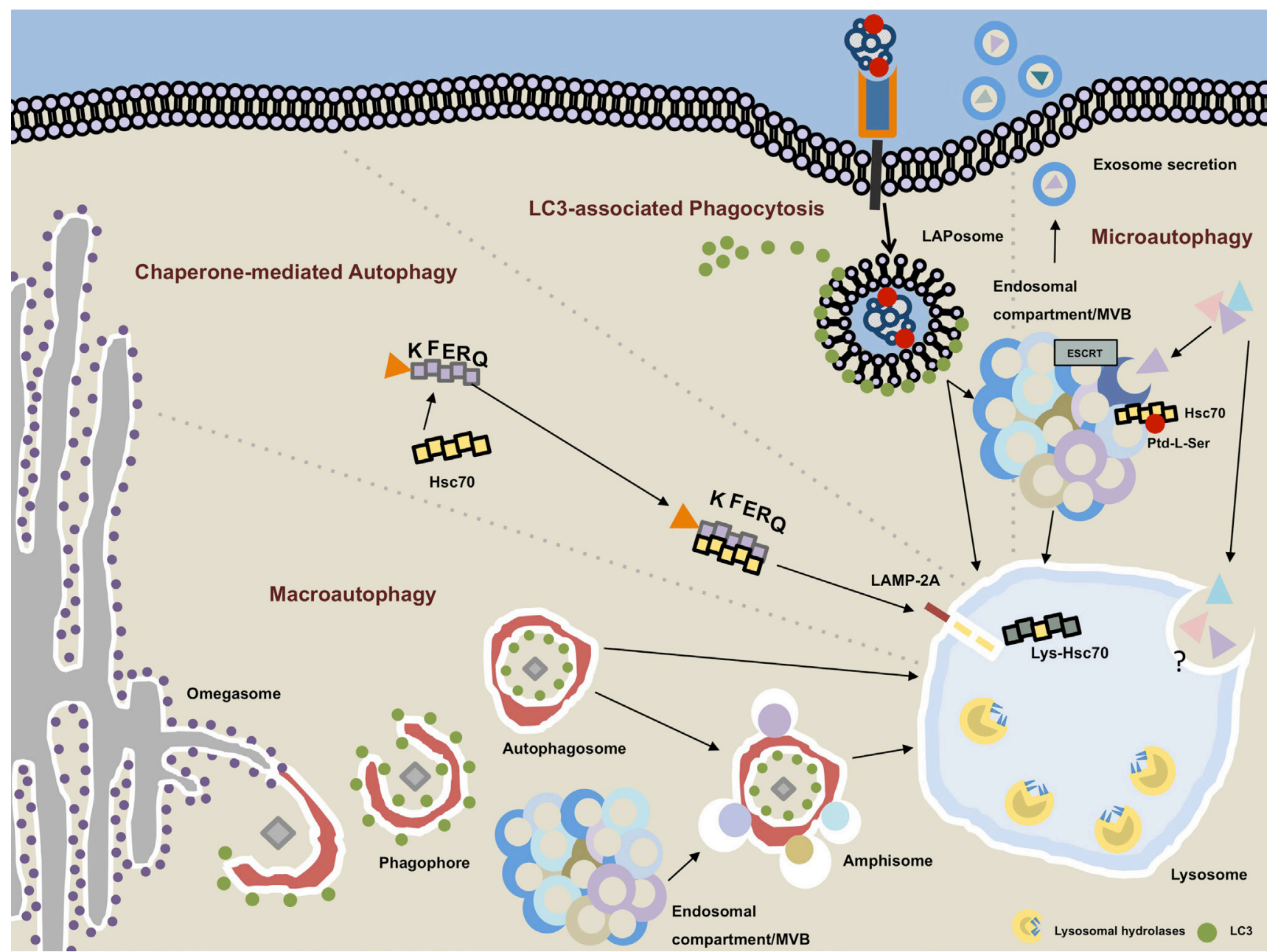

FIGURE 1 | Autophagy pathways converge in the lysosomal compartment. Macroautophagy (MA): the phagophore emanates most likely from endoplasmic reticulum-derived membrane sources at a PI3P-rich (not depicted) structure called the omegasome. Upon recruitment of microtubule-associated protein 1 light chain 3 (LC3) on the outer and inner leaflet of the forming autophagosome, cytoplasmic cargo is engulfed and LC3 removed from the outer membrane as the autophagosome is closed. The completed vesicles may now either be further matured via step-wise fusion with the endocytic compartment resulting in the generation of amphisomes or immediately fuse with hydrolytic enzymes-containing lysosomes. Chaperone-mediated autophagy: target proteins that contain an exposed KFERQ sequence motif are guided in an hsc70-dependent manner toward lysosome-associated membrane protein type 2A (LAMP-2A), which resides in the lysosomal membrane. Upon unfolding of the target protein, LAMP-2A multimers together with lysosomal hsc70 facilitate the transport into the lysosomal lumen. LC3-associated phagocytosis: ligation of an appropriate receptor (e.g., TLR2, Dectin-1, TIM4, etc.) leads to receptor-mediated phagocytosis recruitment and binding of LC3 to the outer membrane of the LAPosome. By analogy with the MA pathway, completed LAPosomes may either fuse with other endocytic vesicles or directly merge with lysosomes. Microautophagy: cytoplasmic cargo can be directly targeted to endosomal compartments/multivesicular bodies (MVB) in an hsc70-, phosphatidylserine (Ptd-L-Ser)-, and endosomal sorting complexes required for transport (ESCRT)-dependent manner. Exosomes containing cytoplasmic material may emanate from the MVB and be secreted into the extracellular space. The molecular events and regulatory processes orchestrating the direct invagination of cytoplasmic constituents into lysosomes remain largely unbeknownst.

complex to autophagosomal initiation sites possibly on tubulovesicular areas comprised of ER and Atg9+ vesicles (46, 49-52). Atg101 may facilitate phosphorylation of Atg13 and minimize its proteasomal degradation $(53,54)$.

\section{The Class III PI3K Complex}

The tetrameric core of this complex consists of vacuolar protein sorting protein (Vps)34 (a phosphoinositide 3 kinase), Vps15 (a regulatory subunit of Vps34 also called p150), Beclin 1 (ortholog of Atg6), and Atg14L (aka Atg14 and Barkor) (27, 55, 56). NRBF2 (ortholog of Atg38) is a recently identified additional subunit of the complex that augments the enzymatic activity of the lipid kinase Vps34 (57-59). The lipid kinase complex is recruited to autophagosomal initiation sites in an ULK1-complex/Atg9dependent manner $(31,60)$.

The key function of the complex is to produce PI3P via Vps34mediated phosphorylation of phosphatidylinositol. Presence and accumulation of PI3P are essential for MA as PI3P-enriched membrane areas then function as platforms to which downstream PI3P-binding partners can be recruited. Regulation of MA occurs 
also on the level of the PI3P complex in that death-associated protein kinase promotes autophagosome formation by unleashing Beclin 1 from the Bcl-2/Bcl-XL complex (61).

\section{Atg2/WIPI Complex and the Atg9 Cycling System}

WIPI1/2 (mammalian ortholog to yeast Atg18) and its binding partner Atg2 are among the PI3P-binding effector molecules that are recruited to PI3P-enriched sites upon PI3PK complex activation (31, 62-64). Since PI3P is present on various subcellular membranes, up until recently it remained a conundrum as of how organelle-specific WIPI-binding is achieved. Studies in yeast have now suggested that WIPI-recruitment to the phagophore requires a dual determinant: PI3P as well as presence of Atg2 (65). The Atg2/WIPI complex is thought to be downstream of the two previous complexes but lateral to the following two conjugation systems (21). Its presence is essential for the formation of autophagosomes probably in part due to recruitment of lipidated LC3 (mammalian ortholog of yeast Atg8) to autophagosomal initiation sites and shielding of lipidated LC3 from Atg4-mediated deconjugation (66).

The transmembrane protein Atg9 can be found in the transGolgi network and on late endosomes under nutrient-rich (hence MA-inactive) conditions (67). Upon starvation (and induced MA activity) however, Atg9 $9^{+}$vesicles translocate from the trans-Golgi network and colocalize with LC3 (67). Possibly, Atg2 and WIPI1/2 mediate Atg9-shuttling between autophagosomal initiation sites and peripheral membrane sources (68). However, its interaction and association with the autophagosome appear to be transient since completed autophagosomes are devoid of Atg9 (69). It was also suggested that local fusion of Atg9 $9^{+}$vesicles operates as an initiation step in the generation of autophagosomes (43). Possibly, Atg9 functions in provision of membrane material for generation of autophagosomes or even removal of early autophagosomal molecules from the site of autophagosome generation (21). The exact interplay between the individual molecules of this unit and their overall function remains subject to further investigation.

\section{The Atg12-Conjugation System}

The first of two ubiquitin-like conjugation systems that orchestrate autophagosome formation consists of the MA-essential molecules Atg12, Atg7, Atg10, Atg5, and Atg16L1 (21). Constitutively and independent of cellular nutrient status, Atg12 is activated via E1-like enzyme Atg7, followed by transfer to E2-like enzyme Atg10 which catalyzes the covalent conjugation of Atg12 to Atg5. Via binding to Atg5, the conjugate then forms a complex with Atg16L1 (70). WIPI2 now attracts the Atg5-Atg12-Atg16L1 complex by means of a recently identified binding site in Atg16L1 to the site of autophagosome generation (71). Additionally, it has been suggested that Atg16L1 is also recruited to the phagophore via binding to ULK-complex member FIP200 $(72,73)$. On site, the complex then functions as an E3-like enzyme for the second conjugation system. The complex is regularly found on the outer membrane of the phagophore but dissociates from there upon completion of the autophagosome (26).

\section{The LC3-Conjugation System}

The second and final conjugation system is comprised of the ubiquitin-like LC3, the hydrolase Atg4, Atg7, and Atg3, which function as E1- and E2-like enzymes, respectively. The pro-form of LC3 is cleaved by Atg4 leading to exposure of a C-terminal glycine residue $(74,75)$. The resulting LC3-I is then lipidated with phosphatidylethanolamine (PE) at said glycine residue by means of Atg3 and Atg7 (76-78). This PE-lipidation of LC3 is assisted by the Atg5-Atg12-conjugates via E3-like activity (70, 79). Additionally, the Atg5-Atg12-Atg16L1-complex guides and determines LC3 to its subcellular destination (79). This lipidated form of LC3, also called LC3-II is initially found symmetrically distributed on the inner and outer membrane of the phagophore $(75,76,80)$. There it appears to aid in elongation of the phagophore as well as coordinate tethering and hemifusion of its membranes and finally the closing of the phagophore to an autophagosome (81-84). Upon vesicle closure, LC3 on the outer membrane is being cleaved from PE via Atg4 while intraluminal LC3 stays associated with the organelle which makes LC3-II to this day a valuable marker for autophagosomes $(80,85)$. In addition to its contribution during membrane reorganization, LC3 mediates MA-cargo selectivity by functioning as an adaptor molecule (86).

\section{REGULATION OF MA}

Most mammalian cells carry out MA on a constitutive level at varying degrees. However, depending on the cell type, macroautophagic activity can be induced and modulated in numerous ways. Primarily nutrient deprivation is a potent stimulus of autophagy and starvation-induced autophagy is a common means to investigate MA under experimental conditions $(87,88)$. The process receives regulatory input on both a systemic and a cellular level (88). Among the most upstream regulatory units of the MA machinery is the antagonistic interplay of coordinate phosphorylation by the two serine/threonine protein kinases AMPK and TORC1 $(44,45)$ (Figure 2). For insights into transcriptional and epigenetic regulation of MA, we kindly refer the reader to excellent recent review articles (89-91).

\section{mTOR/TORC1}

Target of rapamycin complex 1 is one of two functional units of mTOR. Notably, as opposed to TORC2, which has been implicated as an inhibitory entity of CMA activity (92), TORC1 is actually a binding partner for the eponymous rapamycin and is the relevant subunit that participates in negatively regulating MA (93). Various signals that reflect a cell's metabolic status (free amino acids, growth factors, fatty acids, oxygen, etc.) are integrated at the level of TORC1 which, during its activated state, restrains MA via phosphorylation of the upstream MA-machinery members ULK1/2 at serine 757 and ATG13 at serine 258 and is therefore considered a potent negative regulator of MA $(46,47,94)$. In keeping with its cardinal function as a coordinator of metabolic homeostasis, two major inputs for TORC1 downstream signaling are free amino acids and growth factors (88). Growth factors signal via the PI3K-Akt-tuberous sclerosis complex (TSC)1/ TSC2 pathway, eventually leading to disinhibition of the small 


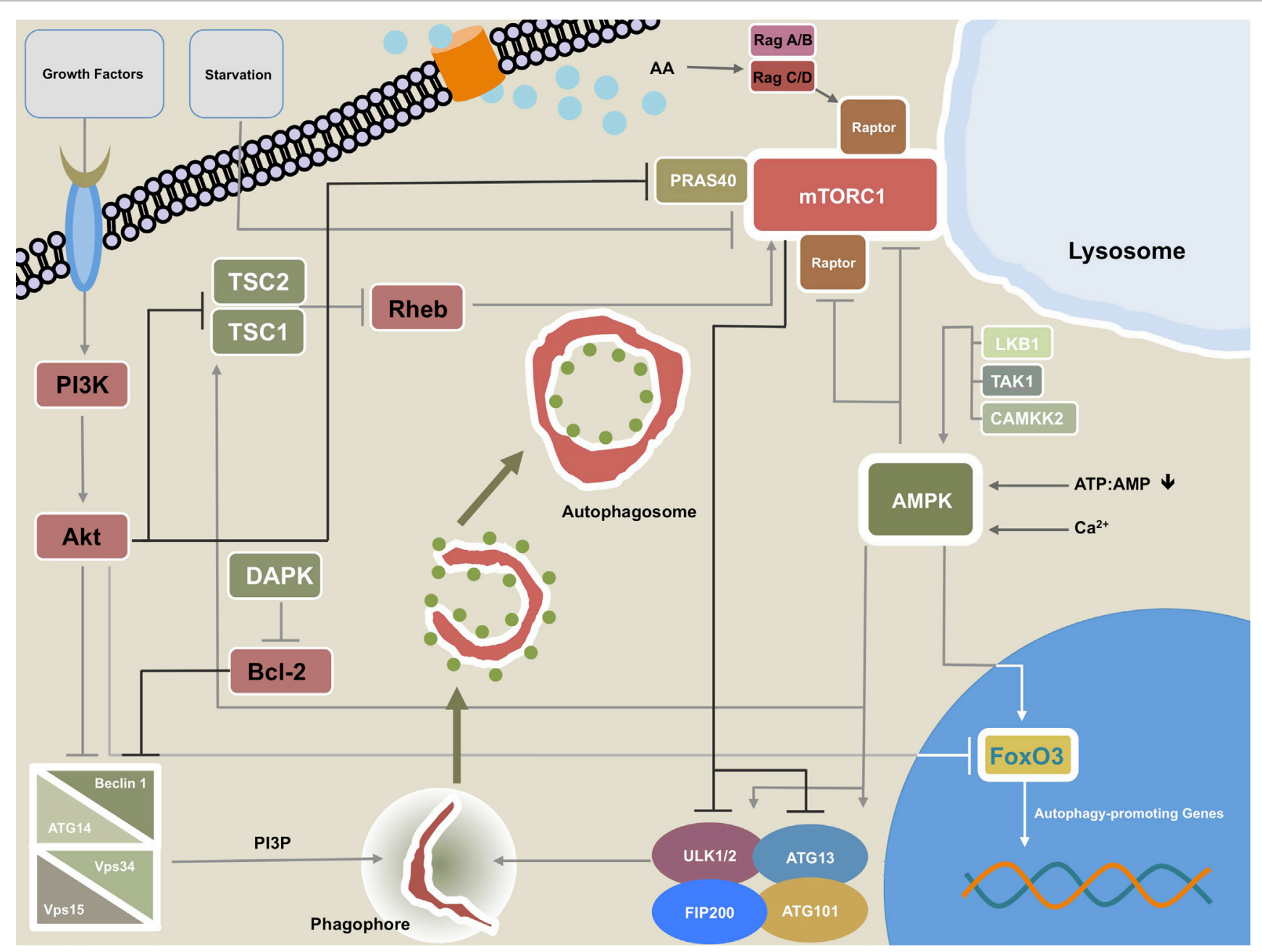

FIGURE 2 | Regulatory network of macroautophagy (MA). This figure illustrates the most important regulatory interplay of molecules that govern MA activity. Growth factors can signal through phosphatidylinositide 3-kinase (PI3K) to Akt, which in turn inhibits the Beclin 1-containing class III PI3K complex. Akt may also repress transcription of autophagy-promoting genes by direct inhibition of transcription factor forkhead box protein O3 (FoxO3). Additionally, Akt reduces macroautophagic activity by inhibiting tuberous sclerosis complex (TSC)1/TSC2. Akt interaction with PRAS40 promotes mTORC1 activity thereby further damping MA. The calcium/calmodulin ( $\left.\mathrm{Ca}^{2+} / \mathrm{CaM}\right)$ serine/threonine kinase death-associated protein kinase (DAPK) fosters MA through phosphorylation of Beclin 1 at T119 which leads to dissociation of Beclin 1 from Bcl-2. The TSC1/TSC2 complex can promote MA by inhibiting the mTORC1 activator and GTPase Ras homolog enriched in brain (Rheb). AMPK and mTORC1 are the two cardinal regulatory units that control MA. mTORC1 may repress the process by phosphorylation of ULK1/2 and/or Atg13. mTORC1 activity is increased by amino acid sensing Rag GTPases via interaction with Raptor. The Rag GTPases also facilitate translocation of mTORC1 to the lysosomal membrane, which serves as a prerequisite for the aforementioned mTORC1-promoting activity of Rheb. AMPK promotes MA by several means: phosphorylation of ULK1/2 and/or Atg13 at different residues than mTORC1, direct interaction with FoxO3, and by directly disinhibiting the inhibitory units, mTORC1 and Raptor. AMPK itself can be triggered by increasing levels of AMP relative to ATP, free $\mathrm{Ca}^{2+}$, and activity of liver kinase B1 (LKB1), transforming growth factor- $\beta$-activating kinase 1 (TAK1), and CAMKK2.

GTPase Ras homolog enriched in brain (Rheb) which then directly activates TORC1 (95-97). Alternatively, the mTOR binding partner proline-rich Akt/PKB substrate $40 \mathrm{kDa}$ (PRAS40) is directly phosphorylated by Akt which in turn leads to revoking of PRAS40-mediated inhibition of mTOR (98). Recently, Akt has been shown to also hamper MA in a direct manner via phosphorylation of Beclin 1 (99). Indirectly, Akt may repress MA via inhibiting forkhead box protein O3 (FoxO3) members-dependent transcription of autophagy-promoting genes (100-102).

Target of rapamycin complex 1 does not directly detect free amino acids and the actual amino acid sensing entity remains yet to be identified (88). Detection of free amino acids by innominate cytoplasmic sensors facilitates the Rag-GTPases-dependent translocation of TORC1 to the lysosomal membrane, which is a spatial requirement for Rheb-mediated activation of TORC1 (88, 103, 104).

\section{AMPK}

AMPK is primarily an energy-sensing kinase that in response to metabolic stress and depleted cellular energy resources such as a low ATP:AMP ratio initiates catabolism (105). In doing so, AMPK is also a positive regulator of MA-mediated proteolysis 
(106). However, even under nutrient-rich conditions AMPK may act toward MA induction in a $\mathrm{Ca}^{2+}$-dependent manner (107, 108). Although essential for starvation-induced MA, AMPK might not suffice as a stand-alone signal but is likely to require additional cues in order to fully initiate MA (107, $108)$. Liver kinase B1, calcium/calmodulin-dependent protein kinase kinase- $\beta$ (CAMKK $\beta$ ), and transforming growth factor- $\beta$ activating kinase 1 are upstream regulators which through phosphorylating its catalytic $\alpha$-subunit activate AMPK (109-113).

AMPK promotes MA by different pathways such as initiation of Rheb inhibition through TSC1/TSC2 (114), phosphorylation of the mTOR binding partner raptor, thereby inhibiting TORC1 (115), or direct phosphorylation of ULK1/2 (at serine 317 and serine 777) or Atg13 (at serine 224) which activates these family members of the upstream MA machinery $(44,45,94)$. Furthermore, AMPK positively regulates MA through activation of the transcriptional factor FoxO3 which in turn transactivates MA-essential genes $(116,117)$.

\section{MICROAUTOPHAGY}

During MI, a vaguely characterized autophagosome-independent process, superfluous cytoplasmic constituents including whole organelles are directly engulfed by surface invaginations of lyso- or endosomal surfaces leading to the budding of cargocontaining microvesicles into the endolysosomal lumina where degradation takes place (118-121) (Figure 1). MI initially has been termed unselective; however, numerous reports in yeast and mammalian cells challenged this concept and described more discerning mechanisms and functions underlying this pathway $(118,120,122)$. For instance, the MI-assisted transport of endosomes to lysosomes appears to be a crucial event during murine embryogenesis in a Rab7-dependent manner (123). Endosomal sorting complexes required for transport (ESCRT)machinery-dependent microlipophagy is essential during cellular adaptation to cell stress caused by disruption of lipidostasis in yeast (124). Schuck and colleagues characterized the specific uptake of compromised ER into the yeast vacuole and coined the term ERphagy (125). Other cargo selective MI entities in yeast include micromitophagy (126, 127), micropexophagy (128, $129)$, and piecemeal microautophagy of the nucleus (130-132). To which extent these processes take place in mammalian cells remains largely obscure (133). Little is known about MI and its regulation on a molecular level in mammalian cells and most findings rely on electron microscope-based morphological alterations such as lysosomal wrapping and flap-like lysosomal membrane extensions (133). The picture becomes even more hazy when acknowledging that some forms of MI require the core machinery needed for MA (see above) but others do not $(120,128,132,134)$. However, distinct cargo selective MI pathways have also been identified in mammalian cells. For instance, heat shock cognate protein of $70 \mathrm{kDa}$ (hsc70)-dependent targeting of cytosolic KFERQ sequence motif-containing proteins into late endosomes and multivesicular bodies (MVB), termed endosomal MI, has recently been identified in murine antigenpresenting cells (APCs) (120). Although this newly characterized process resembles the selective pathway of CMA (see below) into lysosomes, this endosome/MVB-destined MI does not require unfolding of target proteins and is lysosome-associated membrane protein type 2A (LAMP-2A) independent (120). Also different from CMA, endosomal MI is not only dependent on hsc70 but also heavily relies on ESCRT I and III and involves electrostatic binding of hsc70 to negatively charged endosomal phosphatidylserine (Ptd-L-Ser) (120, 135). Fission yeast Nbr1, a partial homolog of mammalian MA receptor NBR1, has been recently identified as a receptor for ESCRT-dependent endosomal MI $(136,137)$. Two recent reports further elaborated on this novel pathway. Mukherjee and colleagues describe an endosomal MI-like process in the fat body of Drosophila melanogaster. In accordance with what had been reported previously, this process is KFERQ- and hsc70-dependent and relies on ESCRT I-, II-, and III-mediated endosomal MVB formation. Although this pathway is independent of MA-machinery members-atg5, atg7, and atg12-it can be induced by prolonged starvation and by mTOR signaling under nutrient-rich conditions (138). A second report shows that by means of its oligomerization capabilities, hsc70 promotes membrane deformations, which supports presynaptic endosomal MI and increases the local turnover of target proteins. Importantly, the degree of presynaptic endosomal MI fosters the release of neurotransmitters into the synapse (139).

Intraluminal vesicles generated within MVBs give rise to exosomes which in a controlled and coordinated manner are released to the extracellular space by most cells $(140,141)$. Aside from their physiological function in cell-to-cell communication and coordinating immune responses, these vesicles of endocytic origin have also been implicated in propagating neurodegenerative processes (141-143). Conclusive evidence points toward a substantial role of endosomal MI in providing cargo for this unique secretory pathway $(120,141)$. It will be of great importance to elucidate the mechanisms and triggers that decide whether MVB content is targeted toward intracellular degradation by the lysosome or instead is fed into the secretory pathway via exosomes.

\section{CHAPERONE-MEDIATED AUTOPHAGY}

Chaperone-mediated autophagy is a selective degradation process devoid of autophagosome formation during which substrate proteins are directly targeted to the lysosome (144) (Figure 1). There is no known equivalent in yeast and evolutionary speaking CMA has emerged only recently, thus far exclusively being identified in mammals (145). Most cells constitutively carry out CMA but the process is upregulated in response to oxidative stress (146), hypoxia (147), DNA damage (148), or protracted nutrient deprivation (149). Unlike MI and MA, which may also handle surplus organelles and non-protein macromolecules, CMA exclusively processes proteins that contain a pentapeptide motif in their amino acid sequence (KFERQ) (150). CMA encompasses at least five distinct steps (1. recognition, 2. binding, 3. unfolding, 4. translocation, 5. disassembly) (144): target proteins bind with their KFERQ-recognition motif to the cytosolic chaperone hsc70 and the substrate:chaperone complex translocates to the lysosomal membrane (recognition) (151). There, LAMP-2A, a 
CMA-receptor, binds the substrate:chaperone complex via its cytosolic tail and subsequently the designated protein undergoes unfolding in a hsc70-dependent manner probably assisted by co-chaperons on the cytosolic side of the lysosome (binding and unfolding) $(152,153)$. Binding of the substrate:chaperone complex to monomeric LAMP-2A not only initiates protein unfolding but also recruitment of further LAMP-2A molecules and subsequent assembly of high molecular weight multimers that then, by help of lysosomal hsc70 (lys-hsc70) enable passage of target proteins to the luminal side of the lysosome (translocation) (154). Upon release of the target protein into the lysosomal lumen, the LAMP-2A multimers are hsp70-dependently broken down into monomers which are then available for another cycle of ligand binding and uptake (disassembly) (154). Recently, more light has been shed on the molecular regulatory pathways controlling CMA. Glial fibrillary acidic protein (GFAP) together with elongation factor $1 \alpha$ tunes assembly and disassembly of the LAMP-2A translocation complexes at the lysosomal membrane (155). Phosphorylation of GFAP by lysosomal Akt1 leads to destabilization of such translocation complexes and consequently reduced CMA activity. The antagonistic interplay between $\mathrm{PH}$ domain leucine-rich repeat-containing protein phosphatase 1 (PHLPP1) as a negative and MTORC2 as a positive regulator upstream of lysosomal Akt1 signaling therefore appears to play a central role in modulating CMA activity (92). Different from MI and MA, CMA processes one molecule at the time and does not require morphological changes of lysosomal membranes such as invaginations, wrapping, flap-like extensions, or fusion with other membranes $(156,157)$. The main rate limiting factor in CMA is abluminal LAMP-2A availability which is regulated by the degree of LAMP-2A degradation by a metalloprotease and cathepsin $\mathrm{A}$ at the site of designated lipid microdomains in the lysosomal membrane (158). As previously mentioned, a prerequisite for CMA processing of a target protein is the presence of an amino acid sequence motif biochemically related to KFERQ (150). In contrast to the biochemical earmarking of a molecule by means of ubiquitination, which may designate the target for proteasomal degradation or recognition by ubiquitin-recognizing adaptor molecules, the KFERQ consensus motif is pre-existing in CMA-target proteins (145). It is therefore likely that the pentapeptide motif is not ubiquitously accessible for binding to hsc70 in order to prevent premature protein translocation to the lysosomal lumen via CMA. Possible mechanisms to condition a target for this destination include but are not limited to, partial unfolding, disassembly of multimers, cleavage of proteins, and posttranslational modifications such as phosphorylation or acetylation of amino acid residues (145, 159, 160). Cytosolic accumulation of aberrant proteins is a hallmark of age-related proteinopathies of the brain and other tissues. A central function of CMA is the removal of misfolded or unwanted proteins and dysfunction in CMA in senescent cells has been implicated in promoting neurodegeneration (161-163). Not considering posttranslational alterations, roughly $30 \%$ of cytosolic proteins bear a sequence motif biochemically related to KFERQ and are therefore potentially subject to CMA-mediated lysosomal degradation $(145,150,151)$. Due to the heterogenous nature of this protein pool it does not come as a surprise that CMA can be regarded as a pivotal gatekeeper in energy homeostasis that also fine-tunes vital cellular processes by limiting key metabolic enzymes (144).

\section{AUTOPHAGOSOME MATURATION AND FUSION WITH THE ENDOLYSOSOMAL SYSTEM}

A hallmark of all autophagic pathways is their convergence into the lysosomal system. During MA, this event requires the coordinated membrane fusion of the autophagosome and endolysosomal vesicles (Figure 1). Prior to terminal fusion with lysosomes, autophagosomes may (or may not) fuse with vesicles of the endocytic compartments like early or late endosomes. The resulting amphisomes subsequently fuse with lysosomes to form autolysosomes. These partly sequential, partly parallel fusion events underscore the dynamic nature of MA. Hence, observed accumulation of autophagosomes needs to be carefully interpreted, for it can mean both bona fide induction of the process and blocked lysosomal fusion.

Autophagosomes are widely distributed throughout the cytoplasm. For these vesicles to fuse with lysosomes and late endosomes (which are predominantly located juxtanuclear), autophagosomes need to be efficiently guided toward this area. Members of the cytoskeleton have been shown to orchestrate the regulated trafficking of autophagosomes from the periphery to sites at which membrane fusion occurs. In fact, microtubules might even aid in autophagosome formation and subsequent fusion with endosomal compartments $(164,165)$. In an antagonistic interplay, the members of the motor protein family dynein/ dynactin complex and kinesin have shown to be involved in guiding autophagosomes alongside microtubules toward lysosomerich areas, a process during which the trafficked vesicles become increasingly acidified as they approach the juxtanuclear area (166, 167). Consequently, disruption of the dynein machinery exacerbates aberrant protein aggregation in experimental models of neurodegeneration due to dysfunctional MA (168). Interestingly, dynamic distribution of lysosomes within the cytoplasm may actually constitute a mechanism by which autophagic flux is regulated (169).

In accordance with general membrane reorganization, also the fusion of autophagosomes with endolysosomal vesicles is in large parts orchestrated by members of small GTPases called Rabs, membrane-tethering complexes, and SNAREs. The molecular specifics have been reviewed in detail elsewhere (170, 171). Studies in yeast suggest that Atg4-mediated cleavage of the LC3 ortholog Atg8 from the outer membrane constitutes one prerequisite that renders the autophagosome ready for fusion $(172,173)$. Possibly, absence of molecules that are involved in the early phase of autophagosome biogenesis functions as yet another signal (170).

Our understanding of the precise molecular events during autophagosome biogenesis and fusion has significantly improved during the last decade and enticing models have been proposed as on how the phagophore is initiated. However, one needs to be cautious as of how the aforementioned molecular interplay of 
Atgs can be generalized since most results were obtained studying starvation-induced MA. There is evidence that autophagosomal biogenesis, and subsequent fusion partners, -sites, and -mechanisms are highly dependent on induction stimulus and cargo (170). Furthermore, the degree as to which these processes are actually carried out in sequence remains enigmatic. It is likely that numerous steps occur in parallel and distinct Atgs might not only carry out a single function but take on several tasks within the cascade. The molecular interactions between Atgs and the kinetics of the process might also significantly differ within the mammalian species and even on a tissue level, there might be specifics to MA that need to be taken into account.

Finally, at least for some Atgs that are essential for MA, an even more promiscuous role has begun to unfold in that these proteins also facilitate MA-independent functions in cellular reprograming, dynamic membrane re-distribution, pathogen clearance, and antigen presentation $(11,174-178)$.

\section{NON-CANONICAL AUTOPHAGY PATHWAYS}

Non-canonical autophagy comprises a set of recently characterized pathways that either result in autophagosome formation but omit the usage of distinct parts of the classical MA-machinery or autophagosome-independent pathways that utilize key components of the MA network $(16,179)$. One can at least differentiate five distinct entities: LC3-associated phagocytosis (LAP), Beclin 1-independent autophagy, autophagosome formation from multiple phagophores and pathogen-specific autophagy modification, autophagy-associated unconventional protein secretion, and defective ribosomal products-containing autophagosome-rich blebs. Here, we focus on LAP, since this pathway has been associated with antigen processing and presentation, and kindly refer the reader for specifics on the other non-canonical autophagy pathways to excellent reviews elsewhere $(16,179,180)$.

\section{LC3-Associated Phagocytosis}

During phagocytosis, a specialized way of endocytosis, cells internalize solid extracellular constituents in a receptor-mediated fashion. The resulting phagosome is being step-wise matured and subsequently fuses with the lysosomal compartment in order to break down the incorporated material (181). Recently, a novel organelle, the single-membraned $\mathrm{LC}^{+}$phagosome or LAPosome, has been identified and the process of its generation and fate was coined LAP (Figure 3) (182, 183). LAP, that links both phagocytosis of extracellular cargo and members of the autophagy molecular core machinery, is initiated by ligation of a variety of extracellular receptors $(12,182,184-186)$. Although some components of the MA machinery are essential for LAP (e.g., Atg5, Atg7, LC3, Beclin 1), the process is independent of others (e.g., the ULK complex including ULK1/2, FIP200, Atg13, Atg101, WIPI1).

LC3-associated phagocytosis-triggering receptors include toll-like receptors (TLRs), Fc-receptors, C-type lectins, and PtdL-Ser-binding receptors (12, 182, 184-186). Upon activation of a LAP-triggering surface receptor, a PI3PK complex that differs in its composition from the one involved in MA, is recruited to the cytosolic membrane of the phagosome followed by the recruitment of the NADPH oxidase NOX2. These events are not preceded by involvement of the canonical ULK complex. The LAP-associated PI3PK complex is made up by Beclin 1, Vps34, and Vps15 (analogous to MA) but is devoid of Atg14 (187). Instead, it includes UVRAG and Rubicon (not members of the canonical PI3PK complex). Similar to MA, the PI3PK complex is set out to generate PI3P on the LAPosome. The association of the modified PI3PK complex on the LAPosome is potentially liaised via Rubicon which, together with PI3P also appears to be key in recruiting, stabilizing, and activating the NADPH oxidase NOX2 to the organelle (187). Rubicon mediates NOX2 stabilization by interaction of its serine-rich domain (AA 567-625) with the NOX2 subunit $\mathrm{p} 22^{\text {phox }}$ whereas PI3P stabilizes the NOX2 subunit $\mathrm{p} 40^{\text {phox }}$ (187, 188). LAPosomal PI3P in concert with NOX2-dependent reactive oxygen species (ROS) production then initiates the two canonical MA conjugation systems (see above), which results in efficient deposition of lipidated LC3 on the outer LAPosomal membrane (187). Consequently, LAP is highly dependent on the MA proteins Atg5, Atg12, Atg16L1, Atg7, Atg3, Atg4, and lipidated LC3. Molecules that have been described to be dispensable for canonical MA but are thought to be essential for LAP include NOX2 and Rubicon (187).

Taken together and in contrast to the canonical MA pathway, during which LC3 conjugation to the phagophore allows for recruitment of cytoplasmic substrates into forming autophagosomes by means of LC3-binding anchor proteins such as p62/ sequestosome 1, LAP handles formerly extracellular particles that access the cell through phagocytosis and occurs without the formation of a double-membraned vesicle and in the absence of p62/sequestosome 1 on $\mathrm{LC}^{+}$single-membraned phagosomes (179, 183, 187).

So far LAP has been implicated in efficient clearance of Saccharomyces cerevisiae and Aspergillus fumigatus (182, 187). However, in the case of Listeria monocytogenes infection, LAPosomes have been described as Listeria-containing compartments that promote persistent infection (189). In plasmacytoid dendritic cells (DCs), LAP, induced upon binding of immune complexes through $\mathrm{Fc} \gamma \mathrm{R}$, is required to assemble the interferon regulatory factor 7 (IRF7)-signaling compartment which is essential for IRF7 activation and subsequent IFN $\alpha$ secretion downstream of TLR9 ligation (186). LysM-Cre ${ }^{+}$conditional knockout mice for LAP-essential proteins mainly target $\mathrm{CD}_{11 \mathrm{~b}^{+} /}$ F4/80+ macrophages and CD11 ${ }^{+} \mathrm{Ly}_{6 \mathrm{G}}{ }^{+}$neutrophils. Aged mice that are deficient of LAP activity in these myeloid subsets spontaneously acquire a lupus-like phenotype (190).

Several questions remain unanswered. The functional benefit of coupling lipidated LC3 to a phagosome is still not completely understood. Some have argued that the coating of the phagosome with LC3-II allows the vesicle to travel faster along microtubules which results in faster fusion with the lysosomal compartment $(182,185,191)$. However, studies that report more rapid cargo degradation were predominantly obtained using murine macrophages. Human studies on the other hand show that in prototypical APCs such as DCs, LAP seems to retain antigenic 


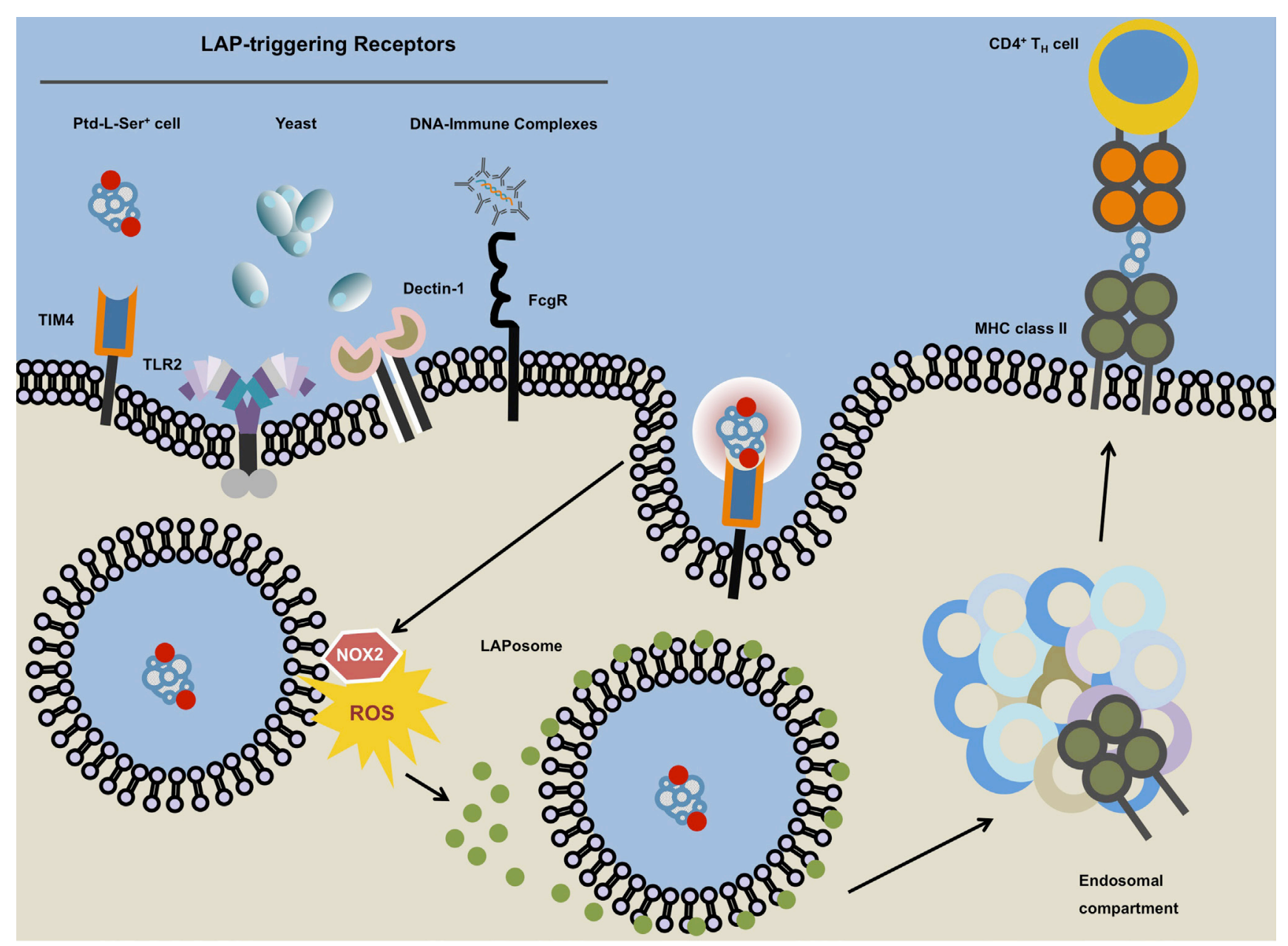

FIGURE 3 | Microtubule-associated protein 1 light chain 3 (LC3)-associated phagocytosis. The ligation of LC3-associated phagocytosis (LAP)-triggering receptors such as phosphatidylserine (Ptd-L-Ser)-recognizing TIM4, TLR2, Dectin-1, or Fcy receptors will ensue receptor-mediated phagocytosis and subsequent phosphatidylinositide 3-kinase-dependent association of the NADPH oxidase NOX2 with the phagosome. The NOX2-derived reactive oxygen species (ROS) and laposomal PI3P (not depicted) mediate the recruitment and binding of LC3 to the outer membrane of the LAPosome. Instead of terminal fusion with the lysosomal compartment, the completed LAPosome may also fuse with endosomal vesicles including major histocompatibility complex (MHC) class II-containing compartments (MIICs) in which after enzymatic digestion, LAPosomal content can be loaded upon MHC class II molecules followed by the presentation of the resulting peptides to $\mathrm{T}_{\mathrm{H}}$ cells.

cargo for sustained MHC class II antigen presentation rather than promoting its degradation (12). Antigenic containment and stabilization in combination with low levels of lysosomal proteases have been speculated to be a crucial mechanism by which DCs maintain efficient and prolonged antigen presentation $(12,183$, 192). Lee and colleagues reported that in murine DCs, TLRdependent phagocytosed HSV-2 can be found in $\mathrm{LC}^{+}$singlemembraned vesicles reminiscent of LAPosomes. In absence of LAP-essential protein Atg5, subsequent HSV-2-specific $\mathrm{CD}_{4}^{+}$ $\mathrm{T}$ cell responses were markedly reduced, arguing for inefficient MHC class II-dependent presentation of LAP-deficient DCs toward cognate $\mathrm{T}$ cells (193). Interestingly, pharmacological induction of canonical MA by TORC1 inhibitor rapamycin did not lead to enhanced MHC class II presentation of viral antigens arguing for a non-MA pathway linking phagocytosis and MHC class II presentation (193).

\section{AUTOPHAGY PATHWAYS IN CNS AUTOIMMUNITY}

Multiple sclerosis is a chronic neuroinflammatory condition during which autoaggressive leukocytes invade across a compromised blood-brain barrier into the CNS. On site, the infiltrated immune cells, in concert with CNS-resident cells mediate progressive axonal demyelination and engender spatio-temporally disseminated lesions within the CNS which entails diffuse cytodegeneration in gray and white matter areas of the CNS (194) (Figure 4).

Experimental autoimmune encephalomyelitis (EAE) is a commonly used animal model of MS in which disease is induced by immunization of animals with myelin-derived antigenic peptides together with adjuvant or by adoptively transferring pre-activated myelin-specific CD4+ T cells in naïve recipients (195-197). EAE is a predominantly $\mathrm{T}$ cell-driven model and a pathomechanistic 


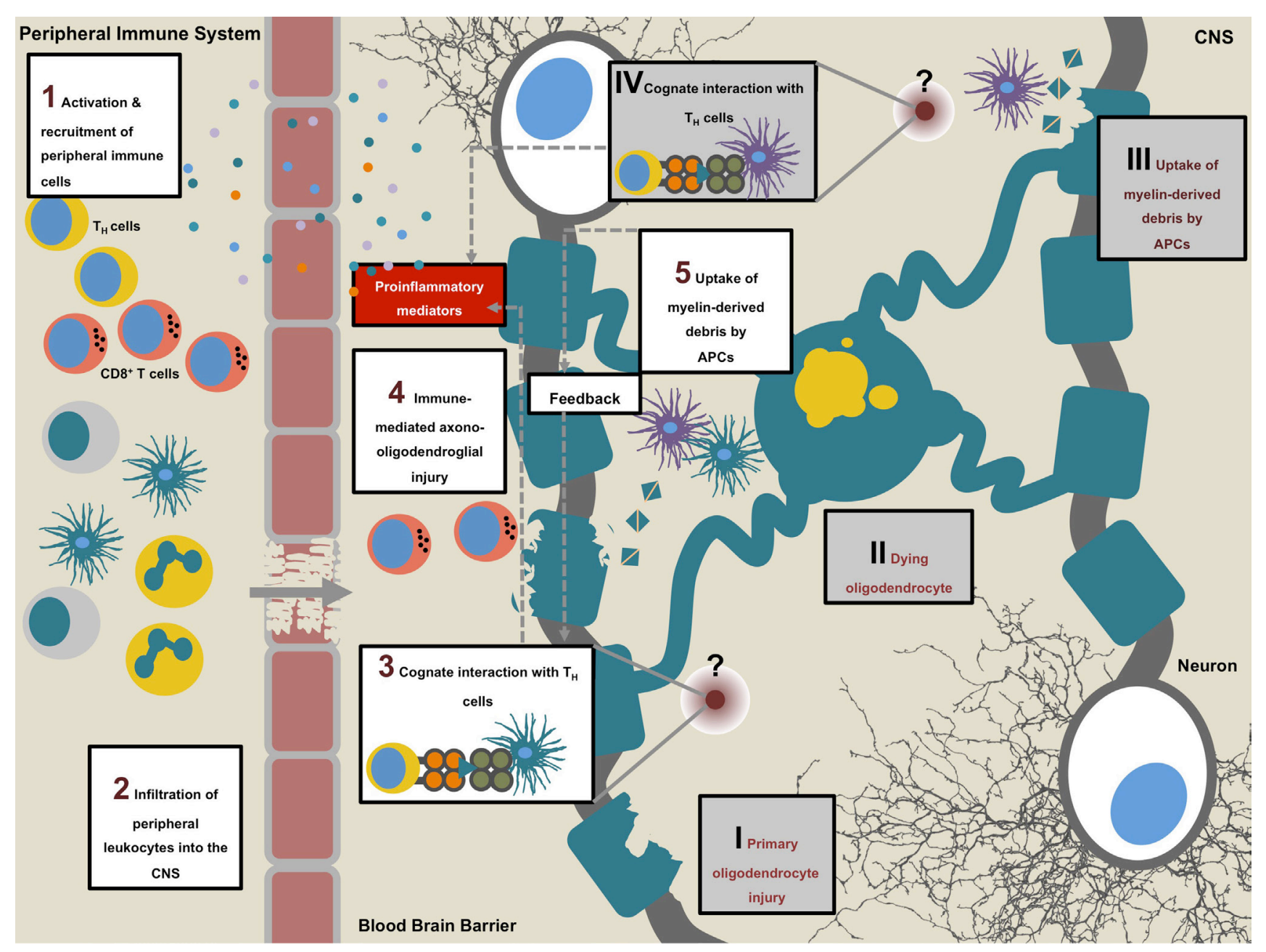

FIGURE 4 | Multiple sclerosis (MS) pathogenesis. Sequence of events that initiates the onset of disease (1-5). MS is suspected to be an autoimmune condition during which peripheral autoaggressive T cells cross into the central nervous system (CNS) where, in concert with other leukocytes, they mediate axono-oligodendroglial damage and unleash a circle of self-perpetuating neuroinflammation (1-5). An alternative to this "outside-in" sequence is the "inside-out" model, which proposes a primary disease triggering event within the CNS (I-IV): primary oligodendrocyte damage of unknown cause may lead to dying and disintegrating oligodendrocytes followed by the uptake of myelin-derived material by CNS-resident antigen-presenting cells (APCs). Upon further intracellular processing of the phagocytosed material, APCs present antigenic myelin-derived peptides to $T_{H}$ cells (at an as of yet unknown site) which in turn initiate influx of peripheral immune cells by secretion of proinflammatory cytokines and chemokines. On site, infiltrating immune cells, including cytotoxic CD8 ${ }^{+} T$ cells and myeloid cells perpetrate secondary oligodendrocyte damage.

prerequisite for CNS damage is the local reactivation of $\mathrm{CD}^{+} \mathrm{T}$ cells specific for myelin-derived antigens (198-202). Reactivated $\mathrm{CD}^{+} \mathrm{T}$ cells together with activated myeloid cells initiate a cascade of proinflammatory events, which is believed to perpetuate CNS tissue damage leading to the development of clinical EAE symptoms (203-205).

How and by which APC subset pathogenic $\mathrm{CD} 4^{+} \mathrm{T}$ cells are being locally reactivated and cause tissue damage during the course of MS and EAE is, however, incompletely understood. This is in part due to the fact that the detailed antigen-processing route of how myelin self-antigens are processed and presented toward $\mathrm{CD} 4^{+} \mathrm{T}$ cells has not been fully elucidated.

Given their diverse, yet often essential functions in immune surveillance, cell survival, proteostasis, antigen presentation, and regulating cellular energy levels, a role for autophagy pathways in the complex pathobiology of MS can been proposed in many aspects of the condition including but not limited to the innate and adaptive branches of the immune system. In the following sections, we will discuss how autophagy pathways potentially interfere with pathogenic adaptive immune responses in MS.

\section{AUTOPHAGY IN T CELLS}

Autophagy has a central but complex role in cell survival in numerous cell types, functioning either as a pro-survival or as a cell death mechanism depending on the cell type, the nature of the death stimulus, and subsequent compensatory changes. Atg5deficient $\mathrm{CD}^{+}{ }^{+}$and $\mathrm{CD} 8^{+} \mathrm{T}$ cells develop normally in the thymus, but fail to repopulate the periphery because of massive cell death and fail to undergo efficient proliferation after $\mathrm{T}$ cell receptor 
stimulation (206). Using a T cell-specific conditional knockout of Beclin 1 (CD4-Cre Beclin $\left.1^{\mathrm{f} / \mathrm{f}}\right)$, Kovacs et al. later elaborated on the underlying mechanism and confirmed that in absence of Beclin 1 in the $\mathrm{CD}^{+} \mathrm{CD}^{+} \mathrm{T}$ cell compartment, homeostasis was disturbed. In line with previous reports, thymic development of the $\mathrm{T}$ cell compartment was normal; however, numbers of $\mathrm{CD}^{+}$ $\mathrm{T}$ cells in secondary lymphoid organs were drastically diminished (>3-fold), whereas CD4 ${ }^{+} \mathrm{T}$ cell were less affected (reduction of $\mathrm{CD}^{+} \mathrm{T}$ cell numbers amounted to $<2$-fold). The steady state fractions of naïve and memory $\mathrm{T}$ cells were unchanged between conditional KO mice and controls. Upon activation with antiCD3/anti-CD28, however, T cells readily underwent apoptosis. Increased susceptibility to cell death was linked to MA-dependent degradation of pro-apoptotic proteins and seems to be differentially relevant in $\mathrm{CD}^{+} \mathrm{T}$ cell subsets (207).

Additionally, Atg16L1-specific deletion in T cells results in spontaneous intestinal inflammation and inbalances of different $\mathrm{T}_{\mathrm{H}}$ cell subsets in the gut. While intestinal $\mathrm{T}$ regulatory cells (TREGs) are drastically reduced in number, IL-13-producing $\mathrm{T}_{\mathrm{H}} 2$ cells expand (208). TREG-specific deletion of Atg5 and Atg7 entailed reduced frequencies and survival of this subset and leads to defective self-tolerance (209).

These data indicate a critical role for the autophagy machinery in lymphocyte development and function and suggest that MA may be essential for both T lymphocyte survival and proliferation in the steady state and after immune activation.

In line with these assumptions, CD4-Cre Beclin $1^{\mathrm{fl} / \mathrm{fl}}$ mice are completely protected from active induction of EAE (207). Interestingly, the defect in the $\mathrm{CD}^{+} \mathrm{T}$ cell compartment during EAE is much more pronounced in the $\mathrm{T}_{\mathrm{H}} 1$ fraction but only mildly present in $\mathrm{T}_{\mathrm{H}} 17$. Subsequent in vitro experiments further confirmed that $\mathrm{T}_{\mathrm{H}} 1$ cells are significantly more prone to undergo apoptosis in absence of autophagy (207).

In addition to the observed protection of EAE upon T cellspecific ablation of autophagy, Atg5 transcript and protein levels in circulating $\mathrm{T}$ cells positively correlated with the disease score in mice that had been actively immunized with $\mathrm{MOG}_{35-55}$ peptide. Furthermore, peripheral T cell-derived RNA analyses suggested a significant increase in Atg5 expression in patients with active relapsing-remitting MS as compared to healthy controls. Atg5 RNA levels in postmortem brain tissue from patients with secondary progressive MS (SPMS) were markedly elevated and strong Atg5 immunoreactivity was observed in confocal microscopy analyses (210).

In contrast to what Kovacs and colleagues had reported, another study that used Beclin 1-deficient Rag1-/- chimeras, found that although Beclin 1 is essential for the maintenance of early lymphocyte progenitor subsets, it is widely expendable for the homeostasis and function of peripheral T and B cells (207, 211). Differential efficiencies of genetic targeting and overall differences in the genetic ablation models may partly account for these discrepancies.

Recently, an additional role for autophagy proteins in the maintenance of $\mathrm{CD}^{+}$memory T cells has emerged. Mice that lack Atg7 in T cells showed reduced CD8 ${ }^{+} \mathrm{T}$ cell-dependent recall responses upon infection with influenza and MCMV (212). Impairment of $\mathrm{CD}^{+} \mathrm{T}$ cell memory in elderly individuals is commonly observed and in part responsible for the reduced efficacy of vaccination with aging (213). Interestingly, Puleston et al. also found reduced levels of autophagic activity in $\mathrm{CD}^{+}$cells of aged mice. Accordingly, upregulation of autophagy with the polyamine spermidine could restore memory $\mathrm{CD}^{+} \mathrm{T}$ cell function to vaccination in aged mice (212). In contrast to what Pua and colleagues had reported previously (206), another study described how $\mathrm{CD}^{+}$cells downregulate autophagic activity upon activation and during proliferation. This was followed by increased activity before the contraction phase. Absence of the autophagy proteins Atg5 and Atg7 lead to impaired formation of a $\mathrm{CD}^{+} \mathrm{T}$ cell memory pool. Moreover, metabolomics analysis disclosed mitochondrial fatty acid oxidation to be dysfunctional in Atg7-deficient T cells at the transition to the memory phase (214).

Aside from the role of autophagy in T cell survival and homeostasis, also CMA has been implicated in regulating $\mathrm{CD}^{+} \mathrm{T}$ cell responses. The negative regulators of TCR signaling, RCAN1, and Itch have been identified as substrates for CMA. Thereby, CMA-controlled degradation of these molecules fine-tunes $\mathrm{T}$ cell responses which is exemplified by the significant reduction in activation-induced proliferation of $\mathrm{CD}^{+} \mathrm{T}$ cells that lack LAMP-2A expression (215). Although so far, dysfunctional CMA in $\mathrm{T}$ cell has not been formally reported to occur in MS or its model systems it is known that mice lacking Itch are prone to develop a hyperactive T cell-driven systemic progressive autoimmune condition (216).

Similar to T cell development, B cells require autophagy both during development and maintenance in the periphery. Atg5deficient pro-B cells do not efficiently develop into pre-B cells, but instead, seem to die at increased frequencies of apoptosis (217). Altogether, these data suggest that highly proliferative lymphocyte compartments during development or in response to immune activation, as seen in autoimmune CNS conditions, require the autophagic machinery to efficiently mobilize nutrients and maintain cellular fitness. However, further studies are needed to clarify differential roles of autophagy pathways in lymphocyte subsets particularly in the context of T cell-driven autoimmunity.

\section{AUTOPHAGY AND ANTIGEN PRESENTATION}

Similar to other autoimmune diseases, HLA-DR and -DQ alleles within the HLA class II region on chromosome 6p21 are by far the strongest risk-conferring genes and are thought to account for $10-60 \%$ of the genetic risk of MS (218). The size of the autoreactive T cell pool is limited by mechanisms of tolerance; however, it is clear that potentially dangerous cells persist in the immune system of healthy individuals without causing damage. Although it is generally accepted that HLA class II molecules influence autoimmune disease risk by regulating the emergence, activation, and expansion of autoreactive $\mathrm{CD} 4^{+} \mathrm{T}$ lymphocytes, our knowledge of how HLA class II-mediated antigen presentation confers risk for autoimmune diseases and regulates $\mathrm{CD} 4^{+} \mathrm{T}$ cell autoreactivity at the molecular level is incompletely understood $(219,220)$.

The cellular architecture of MS lesions is dynamic in its neuropathological features including leukocyte composition (221). 
Commonly, T cell infiltration occurs in two distinct waves (222, 223). Initially, MS lesions are characterized by oligodendrocyte damage and commencing demyelination accompanied by microglia that show an activated phenotype. However, in these initial lesions lymphocytes are scarce. Thereupon progressive demyelination occurs, and myelin constituents are phagocytosed by microglia and other myeloid cells which ensues a dramatic $\mathrm{T}$ cell influx (224).

Onset of EAE is fully dependent on the presence of myelinspecific $\mathrm{T}_{\mathrm{H}}$ cells and local reactivation of these pathogenic culprits is essential in developing CNS autoimmunity (198-202). To this effect, on-site presence and activity of CD11c $\mathrm{c}^{+}$APCs is an instrumental prerequisite for disease induction during the effector phase of EAE (199). Moreover, intravital 2-photon microscopy analyses revealed that during EAE, CD11 $\mathrm{c}^{+}$APCs show a strong proinflammatory phenotype, express a chemokine profile complementary to the chemokine receptor profile expressed on encephalitogenic T cells in the CNS and depict close spatial interactions with these lymphocytes. Hence, depletion of CD $11 \mathrm{c}^{+}$ APCs abrogated enrichment of pathogenic T cells in the CNS and significantly alleviated disease course upon adoptive transfer EAE (225). Active $\mathrm{MOG}_{35-55}$ immunization of mice that lack expression of Atg7 in the CD11 $\mathrm{c}^{+}$compartment results in ameliorated EAE disease course (226). Therefore, further elucidation of the underlying molecular events that drive these cognate interactions between the triad of (CNS resident) APC, myelin antigen, and encephalitogenic $\mathrm{T}$ cell, might unveil new potential therapeutic objectives.

The classical MHC class II pathway, the MA pathway, and LAP are potential degradation pathways resulting in MHC class II presentation of self-antigens. The first compelling evidence for the existence of an endogenous MHC class II pathway came from a study on describing how the endogenous measles virus matrix and nucleocapsid protein-derived antigens could be presented to $\mathrm{CD}^{+} \mathrm{T}$ cells via MHC class II (227). Only 1 year later, Nuchtern et al. confirmed these findings for yet another viral antigen by reporting the efficient loading of influenza A matrix proteinderived peptides onto MHC class II (228). Further proof for the existence of endogenous MHC class II loading pathways was obtained through the direct analysis of peptides bound to MHC class II molecules. In fact, around 30\% of natural ligands eluted from MHC class II molecules from a multitude of cell types were found to be derived from endogenous protein sources (229). In a next step, MA was newly identified as a pathway that delivers endogenous antigenic constituents into MIICs for subsequent recognition by $\mathrm{CD}^{+} \mathrm{T}$ cells $(9,10,230)$. Interestingly, the ability to deliver endogenous antigens to MHC class II seems to be differentially relevant depending on the APC (231). MA is constitutively active in a variety of MHC class II positive APCs such as DCs and B cells $(9,230,232)$ and can be induced following immune stimulation of these cells through germline-encoded pattern-recognition receptors such as TLRs or inflammatory cytokines (233-235). Co-localization studies indicate that in professional APCs, autophagosomes frequently fuse with MIICs, and that experimental delivery of antigens to autophagosomes by targeting the autophagosomal membrane through fusion with LC3 results in robust recognition by antigen-specific $\mathrm{CD} 4^{+} \mathrm{T}$ cells $(10,232)$. Additionally, not only hematopoietic APCs but also thymic epithelial cells expend MA to generate endogenously derived MHC class II-bound peptides for positive selection of $\mathrm{CD}^{+} \mathrm{T}$ cells (236).

Nevertheless, myelin-derived candidate antigens are not known to be expressed in professional APCs therefore an intracellular loading of these peptides onto MHC class II molecules in the context of CNS autoimmunity appears counterintuitive. LAP couples phagocytosis of extracellular solid cargo to key members of the autophagy machinery $(179,187)$. A prerequisite for LAP is the engagement of germline-encoded pattern-recognition receptors or Ptd-L-Ser receptors through phagocytosed material. The role of TLR signaling in the context of EAE has partly been investigated. TLR9 and, to some extend, TLR2 signaling mediates the pathogenicity of EAE, whereas TLR1- and 6-deficiency in mice did not have an impact on the development of active EAE (237, 238). Importantly, also adoptive transfer EAE-induction was dependent on TLR2 signaling, discarding the assumption that microbial-derived constituents in the adjuvant preparation during active EAE serve as ligands (238). Additionally, both studies showed that deficiency of the downstream TLR-signaling molecule myeloid differentiation primary response gene 88 (MyD88) abrogates disease $(237,238)$.

Ample data demonstrate that oligodendrocyte injury and death represented by primary demyelination in absence of inflammatory infiltrates constitute early events in the disease course and are considered specific pathogenic features of MS (239). Sequential MRI analyses revealed that subtle changes in white matter areas can be detected prior to apparent lesions (240). Reduction of macromolecular material and a focal increase of free water could be detected as early as several months before the active lesion occurred. The study's authors concluded that the reduction of magnetization exchange rate was likely to result from primary myelin injury (241). Furthermore, genome-wide epigenetic differences in the DNA methylation status have been reported between normal appearing white matter derived from MS patients and non-diseased control brains (242). The observed hypermethylation and subsequent diminished expression of loci in MS affected brains included genes that control oligodendrocyte survival (BCL2L2 and NDRG1), suggesting that augmented susceptibility to injury precedes inflammatory infiltration. Importantly, a recent study showed that oligodendrocyte death is sufficient to induce encephalitogenic T cell responses and subsequent neuroinflammation in vivo (243). It is therefore conceivable that primary death of oligodendrocytes of yet unknown cause leads to subsequent uptake of myelin-derived antigenic debris by CNS-resident APCs and the following mounting of a myelinspecific adaptive response (244). The non-canonical autophagy pathway LAP may facilitate uptake and ensuing presentation of myelin protein-derived antigenic constituents, thus promoting local reactivation of encephalitogenic $\mathrm{T}_{\mathrm{H}}$ cells.

Particularly early MS lesions depict enhanced gene expression related to ROS production. The most pronounced changes were found for transcripts encoding subunits of the NADPH oxidase complex 2 (NOX2), i.e., CYBA, CYBB, and NCF1, supporting the concept of oxidative stress as a pivotal pathogenic factor particularly early during the disease. NOX2 complex expression is 
detectable in up to $20 \%$ of myeloid cells, predominantly localized in areas of initial tissue damage at the edge of actively demyelinating lesions and is associated with the presence of CNS-infiltrating $\mathrm{T}$ cells suggesting that NOX2 expression by myeloid cells may contribute to CNS inflammation via recruitment or expansion of T cells within MS lesions (245). NOX2 is expressed in macrophages, DCs, microglia, neutrophils, and eosinophils (246). In resting conditions, the enzyme complex is highly glycosylated and resides in intracellular secondary granules and, at lower amounts, in the plasma membrane. After a triggering event, its subunits gp91 and p22 are translocated to the plasma membrane at the site of the forming phagosome, and the cytosolic subunits (p40, p47, p67) are recruited to assemble the active NOX2 complex (247). NOX2 function, generation of ROS, has initially been linked to killing of intraphagosomal pathogens by providing the adequate environment for protease function. In professional APCs, whose principal function is to take up, process and present antigens in order to initiate and shape adaptive immune responses rather than pathogen killing or clearance of cell debris, NOX2 expression was shown to regulate antigen presentation due to its ability to control the level of antigen degradation by altering phagosomal pH levels (248). Indeed, DCs lacking NOX2 show enhanced phagosomal acidification and increased antigen degradation, resulting in impaired cross presentation (248). In addition to cell type-dependent tuning of phagosomal acidification, NOX2 has recently also been implicated in regulating serine and cysteine proteases (cathepsins B, L, and S) within phagosomes (249) and it has been suggested that increased hydrolysis of critical regions within the encephalitogenic $\mathrm{MOG}_{35-55}$ antigen by cysteine cathepsins in the early phagosome contribute to the reduced incidence and delayed onset of EAE reported in NOX2-deficient mice (250). It is conceivable that NOX2 as essential component of the non-canonical autophagy pathway LAP not only affects levels of phagosomal proteolysis as previously shown, but facilitates the induction of an alternative pathway for antigen loading onto MHC class II molecules, thereby contributing to $\mathrm{CD}^{+} \mathrm{T}$ cell-mediated augmentation of autoimmune CNS inflammation.

Altogether, the aforementioned studies suggest that the autophagic machinery could potentially contribute to the initiation and maintenance of $\mathrm{CD}^{+} \mathrm{T}$ cell-driven $\mathrm{CNS}$ tissue injury through delivery of $\mathrm{CD}^{+} \mathrm{T}$ cell antigens into MIICs.

\section{OUTLOOK: AUTOPHAGY PATHWAYS IN CNS AUTOIMMUNITY BEYOND ANTIGEN PRESENTATION AND LYMPHOCYTE SURVIVAL}

There is a profound body of evidence showing that mitochondrial dysfunction is a commonly observed feature in active MS plaques (194, 251-253). In lesions of patients suffering from acute MS, immunohistochemical analyses revealed mitochondrial defects selectively in respiratory chain complex IV subunit COX-I. Mitochondrial damage was observed in oligodendrocytes and axons, but was not present in macrophages or microglia (251). Mitochondria, while being a primary source thereof, are at the same time particularly susceptible to free radical-mediated damage and respiratory chain complex IV subunit COX-I expression is in part regulated by posttranslational modification of mRNA by nitric oxide (NO) (254-256). It has been suggested that myeloid cell-derived secretion of active mediators including $\mathrm{NO}$ in close proximity to oligodendrocytes mediates selective COX-I degradation with subsequent mitochondria impairment (221, 257-260). NMDA-receptor signaling has been shown to induce NADPH oxidase (NOX) activity in oligodendrocyte precursor cells and the subsequent production of ROS can drive both further oligodendrocyte differentiation and myelination $(261,262)$.

Malregulated oligodendrocyte-intrinsic events may also contribute to ROS-mediated mitochondrial damage in oligodendrocytes during MS. Mitochondrial homeostasis (mitostasis) and quality control is ensured by consecutive cycles of fusion and fission tightly coupled to mitophagy-mediated removal of aberrant organelles $(263,264)$ and, complex IV deficiency as well as concomitant cellular energy deficit can in part be compensated for by mitochondrial hyperfusion (265). It is therefore conceivable that malfunctioning of the autophagic axis within this regulatory network leads to disturbance of compensatory mechanisms during free radical induced COX-I deficiency (194, 263). Interestingly, as opposed to the observed functional and morphological impairment of mitochondria in highly active lesions, older and inactive lesions depict enhanced mitochondrial count and activity $(266,267)$.

In comparison to other cell types, neurons depict an unique geometry and organelles such as mitochondria are also needed in distal axonal regions afar from the neuronal soma where mitophagy-mediated lysosomal degradation takes place (268, 269). Duly distribution of mitochondria within axons is critical for neuronal physiology and the constant turnover of dysfunctional specimens in these post-mitotic cells requires well-regulated motor-protein-driven trafficking and anchoring of mitochondria alongside microtubules (269). Temporary increase in mitochondria number, size, and activity as well as subcellular re-location is believed to constitute an axonoprotective mechanism in the light of an elevated energy consumption during chronic axonal injury (270). This compensatory mitochondrial response relies on anchoring molecule syntaphilin, which mediates docking of mitochondria through interaction with microtubules since knockout of syntaphilin results in exacerbated degeneration of demyelinated neurons (270). Syntaphilin-anchored mitochondria have been reported to also recruit Parkin for subsequent mitophagy (268).

In addition to COX-I deficiency observed in acute MS lesions of the white matter, progressive disease also features mitochondrial alterations in deeper cortical areas reminiscent of prototypic neurodegenerative disorders with autophagy-associated pathoetiology such as Alzheimer's disease (AD) and Parkinson's disease (271, 272). Patients suffering from SPMS show significantly higher levels of clonally expanded mtDNA deletions in neurons of layer VI as compared to age-matched controls (272). Increased clonally expanded mtDNA deletions were also observed in layer VI adjacent subcortical white matter which suggests that in both instances soluble factors such as inflammation-associated free radicals in active lesions mediate mitochondrial degeneration. Although this needs to be clearly addressed experimentally, the 
possibility has been raised that accumulations of mtDNA deletions during MS might also yield mutations that could compromise autophagy-mediated quality control of mitochondria (194).

In the process of ATP generation by mitochondrial oxidative phosphorylation, ROS arise that in order to maintain cellular integrity and to prevent oxidative stress, need to be eliminated by means of several antioxidants such as NADPH, cytochrome $c$, and most importantly glutathione (273). However, aside from their detrimental role when produced in large quantities, if not exceedingly present, ROS, occupy also important signaling functions within the cell, interact with redox-sensitive proteins, and work toward maintaining cellular homeostasis in response to cell stress (274). Also Atgs have been described to be sensitive to ROS-mediated posttranslational modification. For example, Atg4 is oxidized and thereby inactivated by $\mathrm{H}_{2} \mathrm{O}_{2}$, which subsequently facilitates conjugation of LC3 to membranes (275). Furthermore, redox-sensitive nuclear transcription factor and histone deacetylase sirtuin 1 (SIRT1), which is highly expressed in neurons, promotes autophagic activity directly by complexing and deacetylation of essential autophagy-machinery proteins and indirectly by deacetylation of FoxO members which in turn leads to promotion of autophagy $(274,276)$.

Portending oxidative damage, strong immunoreactivity for oxidized phospholipids in neurons of active cortical MS lesions has been described to be specific to MS and was not observed to the same degree in tuberculous meningitis, $\mathrm{AD}$, and agematched controls (239). In accordance with these observations, antioxidant enzymes such as superoxide dismutase 1 and 2, heme oxigenase 1, and catalase have been shown to be increased in active MS lesions. Interestingly, this upregulation of antioxidant defense molecules was particularly present in astrocytes and myelin-containing macrophages but not in oligodendrocytes (277). It has been suggested before that the extreme susceptibility of oligodendrocytes to ROS-mediated damage is in part due to insufficient compensatory expression of protective enzymes $(277,278)$.

Increased mitochondrial-derived ROS accumulation and concomitant oxidative damage is believed to constitute a key feature of cellular aging and this process appears to be accelerated and augmented during MS particularly in oligodendrocytes and neurons $(239,279,280)$. In line with this, treatment of aged mice with mTORC1 inhibitor and MA inducer rapamycin increased longevity in mice (281). It is likely that at least in part this effect was mediated by the compound's capability to bridle injurious

\section{REFERENCES}

1. Deter RL, Baudhuin P, De Duve C. Participation of lysosomes in cellular autophagy induced in rat liver by glucagon. J Cell Biol (1967) 35:C11-6.

2. Deter RL, De Duve C. Influence of glucagon, an inducer of cellular autophagy, on some physical properties of rat liver lysosomes. J Cell Biol (1967) 33:437-49.

3. Mizushima N, Komatsu M. Autophagy: renovation of cells and tissues. Cell (2011) 147:728-41. doi:10.1016/j.cell.2011.10.026

4. Komatsu M, Waguri S, Chiba T, Murata S, Iwata J, Tanida I, et al. Loss of autophagy in the central nervous system causes neurodegeneration in mice. Nature (2006) 441:880-4. doi:10.1038/nature04723

5. Hara T, Nakamura K, Matsui M, Yamamoto A, Nakahara Y, SuzukiMigishima R, et al. Suppression of basal autophagy in neural cells causes mitochondrial ROS production and mtDNA accumulation per induction of mitophagy (282).

Whole organelles such as mitochondria are not targeted for lysosomal degradation via LAMP-2A-dependent CMA. However, during cell stress, CMA does participate indirectly in mitochondrial quality control in neurons by removing nonfunctional PARK7, a redox-sensitive glycase with antioxidative properties (283).

In order to target autophagy pathways for therapeutic purposes in MS it will be crucial to fully elucidate the degree to which individual pathways (e.g., MI, MA, CMA, and LAP) contribute to pathology. This will be challenging since impairment of one pathway may lead to both, compensatory responses and concomitant attenuation in the remaining pathways (145). To this end, robust methods need to be established in order reliably distinguish and monitor discrete autophagy pathways. Taken together, these data suggest that regenerative and protective processes in oligodendrocytes and demyelinated axons are highly reliant on meticulously functioning mitochondrial quality control, during which autophagic pathways play a pivotal role $(194,269)$. Future research will show whether the autophagic machinery, in addition to its function in regulating innate and adaptive immune responses, interferes with neurobiological features of MS such as axonal degeneration.

\section{AUTHOR CONTRIBUTIONS}

Both authors have made substantial, intellectual, and equally valuable contribution to the work and approved it for publication.

\section{ACKNOWLEDGMENTS}

The authors thank Christian Münz (University of Zürich, Switzerland) for critically reviewing this manuscript.

\section{FUNDING}

CWK was supported by a Forschungskredit doctoral fellowship (FK-14-021) provided by the University of Zürich. JDL was supported by the Swiss National Foundation (31003A-169664), the Novartis Foundation for medical-biological research, the Sassella Foundation, the Hartmann Müller Foundation, and the Swiss Multiple Sclerosis Society. The authors declare no conflict of interests.

neurodegenerative disease in mice. Nature (2006) 441:885-9. doi:10.1038/ nature 04724

6. Denton D, Nicolson S, Kumar S. Cell death by autophagy: facts and apparent artefacts. Cell Death Differ (2012) 19:87-95. doi:10.1038/cdd. 2011.146

7. Thurston TLM, Wandel MP, von Muhlinen N, Foeglein Á, Randow F. Galectin 8 targets damaged vesicles for autophagy to defend cells against bacterial invasion. Nature (2012) 482:414-8. doi:10.1038/nature10744

8. Saitoh T, Fujita N, Jang MH, Uematsu S, Yang BG, Satoh T, et al. Loss of the autophagy protein Atg16L1 enhances endotoxin-induced IL-1 $\beta$ production. Nature (2008) 456:264-8. doi:10.1038/nature07383

9. Paludan C, Schmid D, Landthaler M, Vockerodt M, Kube D, Tuschl T, et al. Endogenous MHC class II processing of a viral nuclear antigen after autophagy. Science (2005) 307:593-6. doi:10.1126/science.1104904 
10. Schmid D, Pypaert M, Münz C. Antigen-loading compartments for major histocompatibility complex class II molecules continuously receive input from autophagosomes. Immunity (2007) 26:79-92. doi:10.1016/j. immuni.2006.10.018

11. Loi M, Müller A, Steinbach K, Niven J, Barreira da Silva R, Paul P, et al. Macroautophagy proteins control MHC class I levels on dendritic cells and shape anti-viral CD8(+) T cell responses. Cell Rep (2016) 15:1076-87. doi:10.1016/j.celrep.2016.04.002

12. Romao S, Gasser N, Becker AC, Guhl B, Bajagic M, Vanoaica D, et al. Autophagy proteins stabilize pathogen-containing phagosomes for prolonged MHC II antigen processing. J Cell Biol (2013) 203:757-66. doi:10.1083/ jcb. 201308173

13. Babbe H, Roers A, Waisman A, Lassmann H, Goebels N, Hohlfeld R, et al. Clonal expansions of CD8(+) T cells dominate the $\mathrm{T}$ cell infiltrate in active multiple sclerosis lesions as shown by micromanipulation and single cell polymerase chain reaction. J Exp Med (2000) 192:393-404. doi:10.1084/ jem.192.3.393

14. Jacobsen M, Cepok S, Quak E, Happel M, Gaber R, Ziegler A, et al. Oligoclonal expansion of memory CD8+ T cells in cerebrospinal fluid from multiple sclerosis patients. Brain (2002) 125:538-50. doi:10.1093/brain/awf059

15. von Büdingen HC, Kuo TC, Sirota M, van Belle CJ, Apeltsin L, Glanville J, et al. B cell exchange across the blood-brain barrier in multiple sclerosis. J Clin Invest (2012) 122:4533-43. doi:10.1172/JCI63842

16. Codogno P, Mehrpour M, Proikas-Cezanne T. Canonical and non-canonical autophagy: variations on a common theme of self-eating? Nat Rev Mol Cell Biol (2011) 13:7-12. doi:10.1038/nrm3249

17. Mizushima N, Ohsumi Y, Yoshimori T. Autophagosome formation in mammalian cells. Cell Struct Funct (2002) 27:421-9. doi:10.1247/csf.27.421

18. Deretic V. Autophagy in leukocytes and other cells: mechanisms, subsystem organization, selectivity, and links to innate immunity. J Leukoc Biol (2016) 100:969-78. doi:10.1189/jlb.4MR0216-079R

19. Feng Y, He D, Yao Z, Klionsky DJ. The machinery of macroautophagy. Cell Res (2014) 24:24-41. doi:10.1038/cr.2013.168

20. Tsukada M, Ohsumi Y. Isolation and characterization of autophagy-defective mutants of Saccharomyces cerevisiae. FEBS Lett (1993) 333:169-74.

21. Mizushima N, Yoshimori T, Ohsumi Y. The role of Atg proteins in autophagosome formation. Annu Rev Cell Dev Biol (2011) 27:107-32. doi:10.1146/ annurev-cellbio-092910-154005

22. Randow F, Youle RJ. Self and nonself: how autophagy targets mitochondria and bacteria. Cell Host Microbe (2014) 15:403-11. doi:10.1016/ j.chom.2014.03.012

23. Levine B, Mizushima N, Virgin HW. Autophagy in immunity and inflammation. Nature (2011) 469:323-35. doi:10.1038/nature09782

24. Singh R, Kaushik S, Wang Y, Xiang Y, Novak I, Komatsu M, et al. Autophagy regulates lipid metabolism. Nature (2009) 458:1131-5. doi:10.1038/ nature 07976

25. Klionsky DJ, Cuervo AM, Dunn WA Jr, Levine B, van der Klei I, Seglen PO. How shall I eat thee? Autophagy (2007) 3:413-6. doi:10.4161/auto.4377

26. Mizushima N, Yamamoto A, Hatano M, Kobayashi Y, Kabeya Y, Suzuki K, et al. Dissection of autophagosome formation using Apg5-deficient mouse embryonic stem cells. J Cell Biol (2001) 152:657-68. doi:10.1083/jcb.152.4.657

27. Suzuki H, Osawa T, Fujioka Y, Noda NN. Structural biology of the core autophagy machinery. Curr Opin Struct Biol (2016) 43:10-7. doi:10.1016/ j.sbi.2016.09.010

28. Schworer CM, Shiffer KA, Mortimore GE. Quantitative relationship between autophagy and proteolysis during graded amino acid deprivation in perfused rat liver. J Biol Chem (1981) 256:7652-8.

29. Pfeifer U. Inhibition by insulin of the formation of autophagic vacuoles in rat liver. A morphometric approach to the kinetics of intracellular degradation by autophagy. J Cell Biol (1978) 78:152-67.

30. Shibutani ST, Yoshimori T. A current perspective of autophagosome biogenesis. Cell Res (2014) 24:58-68. doi:10.1038/cr.2013.159

31. Itakura E, Mizushima N. Characterization of autophagosome formation site by a hierarchical analysis of mammalian Atg proteins. Autophagy (2010) 6:764-76. doi:10.4161/auto.6.6.12709

32. Axe EL, Walker SA, Manifava M, Chandra P, Roderick HL, Habermann A, et al. Autophagosome formation from membrane compartments enriched in phosphatidylinositol 3-phosphate and dynamically connected to the endoplasmic reticulum. J Cell Biol (2008) 182:685-701. doi:10.1083/jcb.200803137
33. Ylä-Anttila P, Vihinen H, Jokitalo E, Eskelinen E-L. 3D tomography reveals connections between the phagophore and endoplasmic reticulum. Autophagy (2009) 5:1180-5. doi:10.4161/auto.5.8.10274

34. Hayashi-Nishino M, Fujita N, Noda T, Yamaguchi A, Yoshimori T, Yamamoto A. A subdomain of the endoplasmic reticulum forms a cradle for autophagosome formation. Nat Cell Biol (2009) 11:1433-7. doi:10.1038/ncb1991

35. Hailey DW, Rambold AS, Satpute-Krishnan P, Mitra K, Sougrat R, Kim PK, et al. Mitochondria supply membranes for autophagosome biogenesis during starvation. Cell (2010) 141:656-67. doi:10.1016/j.cell.2010.04.009

36. Hamasaki M, Furuta N, Matsuda A, Nezu A, Yamamoto A, Fujita N, et al. Autophagosomes form at ER-mitochondria contact sites. Nature (2013) 495:389-93. doi:10.1038/nature11910

37. Puri C, Renna M, Bento CF, Moreau K, Rubinsztein DC. Diverse autophagosome membrane sources coalesce in recycling endosomes. Cell (2013) 154:1285-99. doi:10.1016/j.cell.2013.08.044

38. Guo Y, Chang C, Huang R, Liu B, Bao L, Liu W. AP1 is essential for generation of autophagosomes from the trans-Golgi network. J Cell Sci (2012) 125:1706-15. doi:10.1242/jcs.093203

39. Zoppino FCM, Militello RD, Slavin I, Alvarez C, Colombo MI. Autophagosome formation depends on the small GTPase Rab1 and functional ER exit sites. Traffic (2010) 11:1246-61. doi:10.1111/j.1600-0854.2010.01086.x

40. Ge L, Melville D, Zhang M, Schekman R. The ER-Golgi intermediate compartment is a key membrane source for the LC3 lipidation step of autophagosome biogenesis. Elife (2013) 2:e00947. doi:10.7554/eLife.00947

41. Ge L, Zhang M, Schekman R. Phosphatidylinositol 3-kinase and COPII generate LC3 lipidation vesicles from the ER-Golgi intermediate compartment. Elife (2014) 3:e04135. doi:10.7554/eLife.04135

42. Ravikumar B, Moreau K, Jahreiss L, Puri C, Rubinsztein DC. Plasma membrane contributes to the formation of pre-autophagosomal structures. Nat Cell Biol (2010) 12:747-57. doi:10.1038/ncb2078

43. Mari M, Griffith J, Rieter E, Krishnappa L, Klionsky DJ, Reggiori F. An Atg9containing compartment that functions in the early steps of autophagosome biogenesis. J Cell Biol (2010) 190:1005-22. doi:10.1083/jcb.200912089

44. Kim J, Kundu M, Viollet B, Guan K-L. AMPK and mTOR regulate autophagy through direct phosphorylation of Ulk1. Nat Cell Biol (2011) 13:132-41. doi: $10.1038 / \mathrm{ncb} 2152$

45. Egan DF, Shackelford DB, Mihaylova MM, Gelino S, Kohnz RA, Mair W, et al. Phosphorylation of ULK1 (hATG1) by AMP-activated protein kinase connects energy sensing to mitophagy. Science (2011) 331:456-61. doi:10.1126/ science.1196371

46. Ganley IG, Lam du H, Wang J, Ding X, Chen S, Jiang X. ULK1.ATG13.FIP200 complex mediates mTOR signaling and is essential for autophagy. J Biol Chem (2009) 284:12297-305. doi:10.1074/jbc.M900573200

47. Hosokawa N, Hara T, Kaizuka T, Kishi C, Takamura A, Miura Y, et al. Nutrientdependent mTORC1 association with the ULK1-Atg13-FIP200 complex required for autophagy. Mol Biol Cell (2009) 20:1981-91. doi:10.1091/mbc. E08-12-1248

48. Hara T, Mizushima N. Role of ULK-FIP200 complex in mammalian autophagy: FIP200, a counterpart of yeast Atg17? Autophagy (2009) 5:85-7. doi:10.4161/auto.5.1.7180

49. Karanasios E, Walker SA, Okkenhaug H, Manifava M, Hummel E, Zimmermann $\mathrm{H}$, et al. Autophagy initiation by ULK complex assembly on ER tubulovesicular regions marked by ATG9 vesicles. Nat Commun (2016) 7:12420. doi:10.1038/ncomms 12420

50. Chang Y-Y, Neufeld TP. An Atg1/Atg13 complex with multiple roles in TOR-mediated autophagy regulation. Mol Biol Cell (2009) 20:2004-14. doi:10.1091/mbc.E08-12-1250

51. Chan EYW, Kir S, Tooze SA. siRNA screening of the kinome identifies ULK1 as a multidomain modulator of autophagy. J Biol Chem (2007) 282:25464-74. doi:10.1074/jbc.M703663200

52. Hara T, Takamura A, Kishi C, Iemura S, Natsume T, Guan JL, et al. FIP200, a ULK-interacting protein, is required for autophagosome formation in mammalian cells. J Cell Biol (2008) 181:497-510. doi:10.1083/jcb.200712064

53. Hosokawa N, Sasaki T, Iemura S, Natsume T, Hara T, Mizushima N. Atg101, a novel mammalian autophagy protein interacting with Atg13. Autophagy (2009) 5:973-9. doi:10.4161/auto.5.7.9296

54. Mercer CA, Kaliappan A, Dennis PB. A novel, human Atg13 binding protein, Atg101, interacts with ULK1 and is essential for macroautophagy. Autophagy (2009) 5:649-62. doi:10.4161/auto.5.5.8249 
55. Itakura E, Kishi C, Inoue K, Mizushima N. Beclin 1 forms two distinct phosphatidylinositol 3-kinase complexes with mammalian Atg14 and UVRAG. Mol Biol Cell (2008) 19:5360-72. doi:10.1091/mbc.E08-01-0080

56. Sun Q, Fan W, Chen K, Ding X, Chen S, Zhong Q. Identification of Barkor as a mammalian autophagy-specific factor for Beclin 1 and class III phosphatidylinositol 3-kinase. Proc Natl Acad Sci U S A (2008) 105:19211-6. doi:10.1073/ pnas.0810452105

57. Araki Y, Ku WC, Akioka M, May AI, Hayashi Y, Arisaka F, et al. Atg38 is required for autophagy-specific phosphatidylinositol 3-kinase complex integrity. J Cell Biol (2013) 203:299-313. doi:10.1083/jcb.201304123

58. Young LN, Cho K, Lawrence R, Zoncu R, Hurley JH. Dynamics and architecture of the NRBF2-containing phosphatidylinositol 3-kinase complex I of autophagy. Proc Natl Acad Sci U S A (2016) 113:8224-9. doi:10.1073/ pnas. 1603650113

59. Ohashi Y, Soler N, García Ortegón M, Zhang L, Kirsten ML, Perisic O, et al. Characterization of Atg38 and NRBF2, a fifth subunit of the autophagic Vps34/PIK3C3 complex. Autophagy (2016) 12:2129-44. doi:10.1080/15548 627.2016 .1226736

60. Matsunaga K, Morita E, Saitoh T, Akira S, Ktistakis NT, Izumi T, et al. Autophagy requires endoplasmic reticulum targeting of the PI3-kinase complex via Atg14L. J Cell Biol (2010) 190:511-21. doi:10.1083/jcb.200911141

61. Zalckvar E, Berissi H, Eisenstein M, Kimchi A. Phosphorylation of Beclin 1 by DAP-kinase promotes autophagy by weakening its interactions with $\mathrm{Bcl}-2$ and Bcl-XL. Autophagy (2009) 5:720-2. doi:10.4161/auto.5.5.8625

62. Obara K, Sekito T, Niimi K, Ohsumi Y. The Atg18-Atg2 complex is recruited to autophagic membranes via phosphatidylinositol 3-phosphate and exerts an essential function. J Biol Chem (2008) 283:23972-80. doi:10.1074/jbc. M803180200

63. Polson HE, de Lartigue J, Rigden DJ, Reedijk M, Urbé S, Clague MJ, et al. Mammalian Atg18 (WIPI2) localizes to omegasome-anchored phagophores and positively regulates LC3 lipidation. Autophagy (2010) 6:506-22. doi:10.4161/auto.6.4.11863

64. Velikkakath AKG, Nishimura T, Oita E, Ishihara N, Mizushima N. Mammalian Atg2 proteins are essential for autophagosome formation and important for regulation of size and distribution of lipid droplets. $\mathrm{Mol} \mathrm{Biol}$ Cell (2012) 23:896-909. doi:10.1091/mbc.E11-09-0785

65. Rieter E, Vinke F, Bakula D, Cebollero E, Ungermann C, Proikas-Cezanne $\mathrm{T}$, et al. Atg18 function in autophagy is regulated by specific sites within its $\beta$-propeller. J Cell Sci (2013) 126:593-604. doi:10.1242/jcs.115725

66. Nair U, Cao Y, Xie Z, Klionsky DJ. Roles of the lipid-binding motifs of Atg18 and Atg21 in the cytoplasm to vacuole targeting pathway and autophagy. J Biol Chem (2010) 285:11476-88. doi:10.1074/jbc.M109.080374

67. Young AR, Chan EY, Hu XW, Köchl R, Crawshaw SG, High S, et al. Starvation and ULK1-dependent cycling of mammalian Atg9 between the TGN and endosomes. J Cell Sci (2006) 119:3888-900. doi:10.1242/jcs.03172

68. Reggiori F, Tucker KA, Stromhaug PE, Klionsky DJ. The Atg1-Atg13 complex regulates Atg9 and Atg23 retrieval transport from the pre-autophagosomal structure. Dev Cell (2004) 6:79-90. doi:10.1016/S1534-5807(03)00402-7

69. Orsi A, Razi M, Dooley HC, Robinson D, Weston AE, Collinson LM, et al. Dynamic and transient interactions of Atg9 with autophagosomes, but not membrane integration, are required for autophagy. Mol Biol Cell (2012) 23:1860-73. doi:10.1091/mbc.E11-09-0746

70. Geng J, Klionsky DJ. The Atg8 and Atg12 ubiquitin-like conjugation systems in macroautophagy. 'Protein modifications: beyond the usual suspects' review series. EMBO Rep (2008) 9:859-64. doi:10.1038/embor.2008.163

71. Dooley HC, Razi M, Polson HE, Girardin SE, Wilson MI, Tooze SA. WIPI2 links LC3 conjugation with PI3P, autophagosome formation, and pathogen clearance by recruiting Atg12-5-16L1. Mol Cell (2014) 55:238-52. doi:10.1016/j.molcel.2014.05.021

72. Gammoh N, Florey O, Overholtzer M, Jiang X. Interaction between FIP200 and ATG16L1 distinguishes ULK1 complex-dependent and -independent autophagy. Nat Struct Mol Biol (2013) 20:144-9. doi:10.1038/nsmb.2475

73. Nishimura T, Kaizuka T, Cadwell K, Sahani MH, Saitoh T, Akira S, et al. FIP200 regulates targeting of Atg16L1 to the isolation membrane. EMBO Rep (2013) 14:284-91. doi:10.1038/embor.2013.6

74. Hemelaar J, Lelyveld VS, Kessler BM, Ploegh HL. A single protease, Apg4B, is specific for the autophagy-related ubiquitin-like proteins GATE-16, MAP1-LC3, GABARAP, and Apg8L. J Biol Chem (2003) 278:51841-50. doi:10.1074/jbc.M308762200
75. Kabeya Y, Mizushima N, Yamamoto A, Oshitani-Okamoto S, Ohsumi Y, Yoshimori T. LC3, GABARAP and GATE16 localize to autophagosomal membrane depending on form-II formation. J Cell Sci (2004) 117:2805-12. doi: $10.1242 /$ jcs.01131

76. Kabeya Y, Mizushima N, Ueno T, Yamamoto A, Kirisako T, Noda T, et al. LC3, a mammalian homologue of yeast Apg8p, is localized in autophagosome membranes after processing. EMBO J (2000) 19:5720-8. doi:10.1093/ emboj/19.21.5720

77. Ichimura Y, Kirisako T, Takao T, Satomi Y, Shimonishi Y, Ishihara N, et al. A ubiquitin-like system mediates protein lipidation. Nature (2000) 408:488-92. doi:10.1038/35044114

78. Tanida I, Sou YS, Ezaki J, Minematsu-Ikeguchi N, Ueno T, Kominami E. HsAtg4B/HsApg4B/autophagin-1 cleaves the carboxyl termini of three human Atg8 homologues and delipidates microtubule-associated protein light chain 3- and GABAA receptor-associated protein-phospholipid conjugates. J Biol Chem (2004) 279:36268-76. doi:10.1074/jbc.M401461200

79. Fujita N, Itoh T, Omori H, Fukuda M, Noda T, Yoshimori T. The Atg16L complex specifies the site of LC3 lipidation for membrane biogenesis in autophagy. Mol Biol Cell (2008) 19:2092-100. doi:10.1091/mbc.E0712-1257

80. Kimura S, Noda T, Yoshimori T. Dissection of the autophagosome maturation process by a novel reporter protein, tandem fluorescent-tagged LC3. Autophagy (2007) 3:452-60. doi:10.4161/auto.4451

81. Nakatogawa H, Ichimura Y, Ohsumi Y. Atg8, a ubiquitin-like protein required for autophagosome formation, mediates membrane tethering and hemifusion. Cell (2007) 130:165-78. doi:10.1016/j.cell.2007.05.021

82. Fujita N, Hayashi-Nishino M, Fukumoto H, Omori H, Yamamoto A, Noda T, et al. An Atg4B mutant hampers the lipidation of LC3 paralogues and causes defects in autophagosome closure. Mol Biol Cell (2008) 19:4651-9. doi:10.1091/mbc.E08-03-0312

83. Weidberg H, Shvets E, Shpilka T, Shimron F, Shinder V, Elazar Z. LC3 and GATE-16/GABARAP subfamilies are both essential yet act differently in autophagosome biogenesis. EMBO J (2010) 29:1792-802. doi:10.1038/ emboj.2010.74

84. Sou YS, Waguri S, Iwata J, Ueno T, Fujimura T, Hara T, et al. The Atg8 conjugation system is indispensable for proper development of autophagic isolation membranes in mice. Mol Biol Cell (2008) 19:4762-75. doi:10.1091/ mbc.E08-03-0309

85. Klionsky DJ, Abdelmohsen K, Abe A, Abedin MJ, Abeliovich H, Acevedo Arozena A, et al. Guidelines for the use and interpretation of assays for monitoring autophagy (3rd edition). Autophagy (2016) 12:1-222. doi:10.1080/ 15548627.2015.1100356

86. Johansen T, Lamark T. Selective autophagy mediated by autophagic adapter proteins. Autophagy (2011) 7:279-96. doi:10.4161/auto.7.3.14487

87. Mizushima N, Klionsky DJ. Protein turnover via autophagy: implications for metabolism. Annu Rev Nutr (2007) 27:19-40. doi:10.1146/annurev. nutr.27.061406.093749

88. Efeyan A, Comb WC, Sabatini DM. Nutrient-sensing mechanisms and pathways. Nature (2015) 517:302-10. doi:10.1038/nature14190

89. Füllgrabe J, Klionsky DJ, Joseph B. The return of the nucleus: transcriptional and epigenetic control of autophagy. Nat Rev Mol Cell Biol (2014) 15:65-74. doi: $10.1038 / \mathrm{nrm} 3716$

90. Lapierre LR, Kumsta C, Sandri M, Ballabio A, Hansen M. Transcriptional and epigenetic regulation of autophagy in aging. Autophagy (2015) 11:867-80. doi:10.1080/15548627.2015.1034410

91. Füllgrabe J, Ghislat G, Cho D-H, Rubinsztein DC. Transcriptional regulation of mammalian autophagy at a glance. J Cell Sci (2016) 129:3059-66. doi:10.1242/jcs. 188920

92. Arias E, Koga H, Diaz A, Mocholi E, Patel B, Cuervo AM. Lysosomal mTORC2/PHLPP1/Akt regulate chaperone-mediated autophagy. Mol Cell (2015) 59:270-84. doi:10.1016/j.molcel.2015.05.030

93. Wullschleger S, Loewith R, Hall MN. TOR signaling in growth and metabolism. Cell (2006) 124:471-84. doi:10.1016/j.cell.2006.01.016

94. Puente C, Hendrickson RC, Jiang X. Nutrient-regulated phosphorylation of ATG13 inhibits starvation-induced autophagy. JBiol Chem (2016) 291:6026-35. doi:10.1074/jbc.M115.689646

95. Long X, Ortiz-Vega S, Lin Y, Avruch J. Rheb binding to mammalian target of rapamycin (mTOR) is regulated by amino acid sufficiency. J Biol Chem (2005) 280:23433-6. doi:10.1074/jbc.C500169200 
96. Long X, Lin Y, Ortiz-Vega S, Yonezawa K, Avruch J. Rheb binds and regulates the mTOR kinase. Curr Biol (2005) 15:702-13. doi:10.1016/j.cub.2005. 02.053

97. Avruch J, Lin Y, Long X, Murthy S, Ortiz-Vega S. Recent advances in the regulation of the TOR pathway by insulin and nutrients. Curr Opin Clin Nutr Metab Care (2005) 8:67-72. doi:10.1097/00075197-200501000-00010

98. Vander Haar E, Lee S-I, Bandhakavi S, Griffin TJ, Kim D-H. Insulin signalling to mTOR mediated by the Akt/PKB substrate PRAS40. Nat Cell Biol (2007) 9:316-23. doi:10.1038/ncb1547

99. Wang RC, Wei Y, An Z, Zou Z, Xiao G, Bhagat G, et al. Akt-mediated regulation of autophagy and tumorigenesis through Beclin 1 phosphorylation. Science (2012) 338:956-9. doi:10.1126/science.1225967

100. Guo S, Sonenshein GE. Forkhead box transcription factor FOXO3a regulates estrogen receptor alpha expression and is repressed by the Her-2/neu/ phosphatidylinositol 3-kinase/Akt signaling pathway. Mol Cell Biol (2004) 24:8681-90. doi:10.1128/MCB.24.19.8681-8690.2004

101. Brunet A, Bonni A, Zigmond MJ, Lin MZ, Juo P, Hu LS, et al. Akt promotes cell survival by phosphorylating and inhibiting a forkhead transcription factor. Cell (1999) 96:857-68.

102. Das TP, Suman S, Alatassi H, Ankem MK, Damodaran C. Inhibition of AKT promotes FOXO3a-dependent apoptosis in prostate cancer. Cell Death Dis (2016) 7:e2111. doi:10.1038/cddis.2015.403

103. Sancak Y, Bar-Peled L, Zoncu R, Markhard AL, Nada S, Sabatini DM. Ragulator-Rag complex targets mTORC1 to the lysosomal surface and is necessary for its activation by amino acids. Cell (2010) 141:290-303. doi:10.1016/j.cell.2010.02.024

104. Betz C, Hall MN. Where is mTOR and what is it doing there? J Cell Biol (2013) 203:563-74. doi:10.1083/jcb.201306041

105. Hardie DG. AMP-activated/SNF1 protein kinases: conserved guardians of cellular energy. Nat Rev Mol Cell Biol (2007) 8:774-85. doi:10.1038/nrm2249

106. Meley D, Bauvy C, Houben-Weerts JH, Dubbelhuis PF, Helmond MT, Codogno P, et al. AMP-activated protein kinase and the regulation of autophagic proteolysis. J Biol Chem (2006) 281:34870-9. doi:10.1074/jbc. M605488200

107. Høyer-Hansen M, Bastholm L, Szyniarowski P, Campanella M, Szabadkai G, Farkas T, et al. Control of macroautophagy by calcium, calmodulin-dependent kinase kinase-beta, and Bcl-2. Mol Cell (2007) 25:193-205. doi:10.1016/j. molcel.2006.12.009

108. Høyer-Hansen M, Jäättelä M. AMP-activated protein kinase: a universal regulator of autophagy? Autophagy (2007) 3:381-3.

109. Shaw RJ, Kosmatka M, Bardeesy N, Hurley RL, Witters LA, DePinho RA, et al. The tumor suppressor LKB1 kinase directly activates AMP-activated kinase and regulates apoptosis in response to energy stress. Proc Natl Acad Sci U S A (2004) 101:3329-35. doi:10.1073/pnas.0308061100

110. Hong S-P, Leiper FC, Woods A, Carling D, Carlson M. Activation of yeast Snf1 and mammalian AMP-activated protein kinase by upstream kinases. Proc Natl Acad Sci U S A (2003) 100:8839-43. doi:10.1073/pnas.1533136100

111. Woods A, Johnstone SR, Dickerson K, Leiper FC, Fryer LG, Neumann D, et al. LKB1 is the upstream kinase in the AMP-activated protein kinase cascade. Curr Biol (2003) 13:2004-8. doi:10.1016/j.cub.2003.10.031

112. Herrero-Martín G, Høyer-Hansen M, García-García C, Fumarola C, Farkas T, López-Rivas A, et al. TAK1 activates AMPK-dependent cytoprotective autophagy in TRAIL-treated epithelial cells. EMBO J (2009) 28:677-85. doi:10.1038/emboj.2009.8

113. Hawley SA, Pan DA, Mustard KJ, Ross L, Bain J, Edelman AM, et al. Calmodulin-dependent protein kinase kinase-beta is an alternative upstream kinase for AMP-activated protein kinase. Cell Metab (2005) 2:9-19. doi:10.1016/j.cmet.2005.05.009

114. Inoki K, Zhu T, Guan K-L. TSC2 mediates cellular energy response to control cell growth and survival. Cell (2003) 115:577-90. doi:10.1016/ S0092-8674(03)00929-2

115. Gwinn DM, Shackelford DB, Egan DF, Mihaylova MM, Mery A, Vasquez DS, et al. AMPK phosphorylation of raptor mediates a metabolic checkpoint. Mol Cell (2008) 30:214-26. doi:10.1016/j.molcel.2008.03.003

116. Sanchez AM, Csibi A, Raibon A, Cornille K, Gay S, Bernardi H, et al. AMPK promotes skeletal muscle autophagy through activation of forkhead FoxO3a and interaction with Ulk1. J Cell Biochem (2012) 113:695-710. doi:10.1002/jcb.23399
117. Mammucari C, Milan G, Romanello V, Masiero E, Rudolf R, Del Piccolo P, et al. FoxO3 controls autophagy in skeletal muscle in vivo. Cell Metab (2007) 6:458-71. doi:10.1016/j.cmet.2007.11.001

118. Li W-W, Li J, Bao J-K. Microautophagy: lesser-known self-eating. Cell Mol Life Sci (2012) 69:1125-36. doi:10.1007/s00018-011-0865-5

119. Farré J-C, Krick R, Subramani S, Thumm M. Turnover of organelles by autophagy in yeast. Curr Opin Cell Biol (2009) 21:522-30. doi:10.1016/ j.ceb.2009.04.015

120. Sahu R, Kaushik S, Clement CC, Cannizzo ES, Scharf B, Follenzi A, et al. Microautophagy of cytosolic proteins by late endosomes. Dev Cell (2011) 20:131-9. doi:10.1016/j.devcel.2010.12.003

121. Marzella L, Ahlberg J, Glaumann H. Autophagy, heterophagy, microautophagy and crinophagy as the means for intracellular degradation. Virchows Arch B Cell Pathol Incl Mol Pathol (1981) 36:219-34.

122. Santambrogio L, Cuervo AM. Chasing the elusive mammalian microautophagy. Autophagy (2011) 7:652-4. doi:10.4161/auto.7.6.15287

123. Kawamura N, Sun-Wada GH, Aoyama M, Harada A, Takasuga S, Sasaki T, et al. Delivery of endosomes to lysosomes via microautophagy in the visceral endoderm of mouse embryos. Nat Commun (2012) 3:1071. doi:10.1038/ ncomms 2069

124. Vevea JD, Garcia EJ, Chan RB, Zhou B, Schultz M, Di Paolo G, et al. Role for lipid droplet biogenesis and microlipophagy in adaptation to lipid imbalance in yeast. Dev Cell (2015) 35:584-99. doi:10.1016/j.devcel.2015. 11.010

125. Schuck S, Gallagher CM, Walter P. ER-phagy mediates selective degradation of endoplasmic reticulum independently of the core autophagy machinery. J Cell Sci (2014) 127:4078-88. doi:10.1242/jcs.154716

126. Priault M, Salin B, Schaeffer J, Vallette FM, di Rago JP, Martinou JC. Impairing the bioenergetic status and the biogenesis of mitochondria triggers mitophagy in yeast. Cell Death Differ (2005) 12:1613-21. doi:10.1038/sj.cdd.4401697

127. Bhatia-Kiššová I, Camougrand N. Mitophagy in yeast: actors and physiological roles. FEMS Yeast Res (2010) 10:1023-34. doi:10.1111/ j.1567-1364.2010.00659.x

128. Manjithaya R, Nazarko TY, Farré J-C, Subramani S. Molecular mechanism and physiological role of pexophagy. FEBS Lett (2010) 584:1367-73. doi:10.1016/j.febslet.2010.01.019

129. Dunn WA Jr, Cregg JM, Kiel JA, van der Klei IJ, Oku M, Sakai Y, et al. Pexophagy: the selective autophagy of peroxisomes. Autophagy (2005) 1:75-83. doi:10.4161/auto.1.2.1737

130. Roberts P, Moshitch-Moshkovitz S, Kvam E, O’Toole E, Winey M, Goldfarb DS. Piecemeal microautophagy of nucleus in Saccharomyces cerevisiae. Mol Biol Cell (2003) 14:129-41. doi:10.1091/mbc.E02-08-0483

131. Krick R, Mühe Y, Prick T, Bredschneider M, Bremer S, Wenzel D, et al. Piecemeal microautophagy of the nucleus: genetic and morphological traits. Autophagy (2009) 5:270-2. doi:10.4161/auto.5.2.7639

132. Krick R, Muehe Y, Prick T, Bremer S, Schlotterhose P, Eskelinen EL, et al. Piecemeal microautophagy of the nucleus requires the core macroautophagy genes. Mol Biol Cell (2008) 19:4492-505. doi:10.1091/mbc.E08-04-0363

133. Mijaljica D, Prescott M, Devenish RJ. Microautophagy in mammalian cells: revisiting a 40-year-old conundrum. Autophagy (2011) 7:673-82. doi:10.4161/auto.7.7.14733

134. Shpilka T, Elazar Z. Shedding light on mammalian microautophagy. Dev Cell (2011) 20:1-2. doi:10.1016/j.devcel.2010.12.010

135. Morozova K, Clement CC, Kaushik S, Stiller B, Arias E, Ahmad A, et al. Structural and biological interaction of hsc-70 protein with phosphatidylserine in endosomal microautophagy. J Biol Chem (2016) 291:18096-106. doi:10.1074/jbc.M116.736744

136. Liu XM, Sun LL, Hu W, Ding YH, Dong MQ, Du LL. ESCRTs cooperate with a selective autophagy receptor to mediate vacuolar targeting of soluble cargos. Mol Cell (2015) 59:1035-42. doi:10.1016/j.molcel.2015.07.034

137. Mizushima N. Nbr1, a receptor for ESCRT-dependent endosomal microautophagy in fission yeast. Mol Cell (2015) 59:887-9. doi:10.1016/ j.molcel.2015.09.004

138. Mukherjee A, Patel B, Koga H, Cuervo AM, Jenny A. Selective endosomal microautophagy is starvation-inducible in Drosophila. Autophagy (2016) 12:1984-99. doi:10.1080/15548627.2016.1208887

139. Uytterhoeven V, Lauwers E, Maes I, Miskiewicz K, Melo MN, Swerts J, et al. Hsc70-4 deforms membranes to promote synaptic protein turnover 
by endosomal microautophagy. Neuron (2015) 88:735-48. doi:10.1016/ j.neuron.2015.10.012

140. Howitt J, Hill AF. Exosomes in the pathology of neurodegenerative diseases. J Biol Chem (2016) 291:26589-97. doi:10.1074/jbc.R116.757955

141. Baixauli F, López-Otín C, Mittelbrunn M. Exosomes and autophagy: coordinated mechanisms for the maintenance of cellular fitness. Front Immunol (2014) 5:403. doi:10.3389/fimmu.2014.00403

142. Robbins PD, Morelli AE. Regulation of immune responses by extracellular vesicles. Nat Rev Immunol (2014) 14:195-208. doi:10.1038/nri3622

143. Brettschneider J, Del Tredici K, Lee VM-Y, Trojanowski JQ. Spreading of pathology in neurodegenerative diseases: a focus on human studies. Nat Rev Neurosci (2015) 16:109-20. doi:10.1038/nrn3887

144. Tasset I, Cuervo AM. Role of chaperone-mediated autophagy in metabolism. FEBS J (2016) 283:2403-13. doi:10.1111/febs.13677

145. Kaushik S, Cuervo AM. Chaperone-mediated autophagy: a unique way to enter the lysosome world. Trends Cell Biol (2012) 22:407-17. doi:10.1016/ j.tcb.2012.05.006

146. Kiffin R, Christian C, Knecht E, Cuervo AM. Activation of chaperonemediated autophagy during oxidative stress. Mol Biol Cell (2004) 15:4829-40. doi:10.1091/mbc.E04-06-0477

147. Hubbi ME, Hu H, Kshitiz, Ahmed I, Levchenko A, Semenza GL. Chaperonemediated autophagy targets hypoxia-inducible factor-1 $\alpha$ (HIF-1 $\alpha$ ) for lysosomal degradation. J Biol Chem (2013) 288:10703-14. doi:10.1074/jbc. M112.414771

148. Park C, Suh Y, Cuervo AM. Regulated degradation of Chk1 by chaperone-mediated autophagy in response to DNA damage. Nat Commun (2015) 6:6823. doi:10.1038/ncomms7823

149. Cuervo AM, Knecht E, Terlecky SR, Dice JF. Activation of a selective pathway of lysosomal proteolysis in rat liver by prolonged starvation. Am J Physiol (1995) 269:C1200-8.

150. Dice JF. Peptide sequences that target cytosolic proteins for lysosomal proteolysis. Trends Biochem Sci (1990) 15:305-9.

151. Chiang HL, Terlecky SR, Plant CP, Dice JF. A role for a 70-kilodalton heat shock protein in lysosomal degradation of intracellular proteins. Science (1989) 246:382-5.

152. Cuervo AM, Dice JF. A receptor for the selective uptake and degradation of proteins by lysosomes. Science (1996) 273:501-3.

153. Salvador N, Aguado C, Horst M, Knecht E. Import of a cytosolic protein into lysosomes by chaperone-mediated autophagy depends on its folding state. J Biol Chem (2000) 275:27447-56. doi:10.1074/jbc.M001394200

154. Bandyopadhyay U, Kaushik S, Varticovski L, Cuervo AM. The chaperonemediated autophagy receptor organizes in dynamic protein complexes at the lysosomal membrane. Mol Cell Biol (2008) 28:5747-63. doi:10.1128/ MCB.02070-07

155. Bandyopadhyay U, Sridhar S, Kaushik S, Kiffin R, Cuervo AM. Identification of regulators of chaperone-mediated autophagy. Mol Cell (2010) 39:535-47. doi:10.1016/j.molcel.2010.08.004

156. Bandyopadhyay U, Cuervo AM. Chaperone-mediated autophagy in aging and neurodegeneration: lessons from alpha-synuclein. Exp Gerontol (2007) 42:120-8. doi:10.1016/j.exger.2006.05.019

157. Massey A, Kiffin R, Cuervo AM. Pathophysiology of chaperone-mediated autophagy. Int J Biochem Cell Biol (2004) 36:2420-34. doi:10.1016/j. biocel.2004.04.010

158. Kaushik S, Massey AC, Cuervo AM. Lysosome membrane lipid microdomains: novel regulators of chaperone-mediated autophagy. EMBO J (2006) 25:3921-33. doi:10.1038/sj.emboj.7601283

159. Thompson LM, Aiken CT, Kaltenbach LS, Agrawal N, Illes K, Khoshnan A, et al. IKK phosphorylates huntingtin and targets it for degradation by the proteasome and lysosome. J Cell Biol (2009) 187:1083-99. doi:10.1083/ jcb.200909067

160. Lv L, Li D, Zhao D, Lin R, Chu Y, Zhang H, et al. Acetylation targets the M2 isoform of pyruvate kinase for degradation through chaperone-mediated autophagy and promotes tumor growth. Mol Cell (2011) 42:719-30. doi:10.1016/j.molcel.2011.04.025

161. Cuervo AM, Stefanis L, Fredenburg R, Lansbury PT, Sulzer D. Impaired degradation of mutant alpha-synuclein by chaperone-mediated autophagy. Science (2004) 305:1292-5. doi:10.1126/science.1101738

162. Martinez-Vicente M, Talloczy Z, Kaushik S, Massey AC, Mazzulli J, Mosharov EV, et al. Dopamine-modified alpha-synuclein blocks chaperone-mediated autophagy.J Clin Invest (2008) 118:777-88. doi:10.1172/ JCI32806

163. Orenstein SJ, Kuo SH, Tasset I, Arias E, Koga H, Fernandez-Carasa I, et al. Interplay of LRRK2 with chaperone-mediated autophagy. Nat Neurosci (2013) 16:394-406. doi:10.1038/nn.3350

164. Fass E, Shvets E, Degani I, Hirschberg K, Elazar Z. Microtubules support production of starvation-induced autophagosomes but not their targeting and fusion with lysosomes. J Biol Chem (2006) 281:36303-16. doi:10.1074/ jbc.M607031200

165. Köchl R, Hu XW, Chan EYW, Tooze SA. Microtubules facilitate autophagosome formation and fusion of autophagosomes with endosomes. Traffic (2006) 7:129-45. doi:10.1111/j.1600-0854.2005.00368.x

166. Kimura S, Noda T, Yoshimori T. Dynein-dependent movement of autophagosomes mediates efficient encounters with lysosomes. Cell Struct Funct (2008) 33:109-22. doi:10.1247/csf.08005

167. Maday S, Wallace KE, Holzbaur ELF. Autophagosomes initiate distally and mature during transport toward the cell soma in primary neurons. J Cell Biol (2012) 196:407-17. doi:10.1083/jcb.201106120

168. Ravikumar B, Acevedo-Arozena A, Imarisio S, Berger Z, Vacher C, O'Kane $\mathrm{CJ}$, et al. Dynein mutations impair autophagic clearance of aggregate-prone proteins. Nat Genet (2005) 37:771-6. doi:10.1038/ng1591

169. Korolchuk VI, Saiki S, Lichtenberg M, Siddiqi FH, Roberts EA, Imarisio S, et al. Lysosomal positioning coordinates cellular nutrient responses. Nat Cell Biol (2011) 13:453-60. doi:10.1038/ncb2204

170. Ganley IG. Autophagosome maturation and lysosomal fusion. Essays Biochem (2013) 55:65-78. doi:10.1042/bse0550065

171. Hyttinen JMT, Niittykoski M, Salminen A, Kaarniranta K. Maturation of autophagosomes and endosomes: a key role for Rab7. Biochim Biophys Acta (2013) 1833:503-10. doi:10.1016/j.bbamcr.2012.11.018

172. Nair U, Yen WL, Mari M, Cao Y, Xie Z, Baba M, et al. A role for Atg8-PE deconjugation in autophagosome biogenesis. Autophagy (2012) 8:780-93. doi:10.4161/auto.19385

173. Yu ZQ, Ni T, Hong B, Wang HY, Jiang FJ, Zou S, et al. Dual roles of Atg8-PE deconjugation by Atg4 in autophagy. Autophagy (2012) 8:883-92. doi:10.4161/auto.19652

174. Zhao Z, Fux B, Goodwin M, Dunay IR, Strong D, Miller BC, et al. Autophagosome-independent essential function for the autophagy protein Atg5 in cellular immunity to intracellular pathogens. Cell Host Microbe (2008) 4:458-69. doi:10.1016/j.chom.2008.10.003

175. Kroemer G, Levine B. Autophagic cell death: the story of a misnomer. Nat Rev Mol Cell Biol (2008) 9:1004-10. doi:10.1038/nrm2529

176. Radoshevich L, Murrow L, Chen N, Fernandez E, Roy S, Fung C, et al. ATG12 conjugation to ATG3 regulates mitochondrial homeostasis and cell death. Cell (2010) 142:590-600. doi:10.1016/j.cell.2010.07.018

177. Subramani S, Malhotra V. Non-autophagic roles of autophagy-related proteins. EMBO Rep (2013) 14:143-51. doi:10.1038/embor.2012.220

178. Kimmey JM, Huynh JP, Weiss LA, Park S, Kambal A, Debnath J, et al. Unique role for ATG5 in neutrophil-mediated immunopathology during M. tuberculosis infection. Nature (2015) 528:565-9. doi:10.1038/ nature 16451

179. Münz C. Of LAP, CUPS, and DRibbles - unconventional use of autophagy proteins for MHC restricted antigen presentation. Front Immunol (2015) 6:200. doi:10.3389/fimmu.2015.00200

180. Cadwell K. Crosstalk between autophagy and inflammatory signalling pathways: balancing defence and homeostasis. Nat Rev Immunol (2016) 16:661-75. doi:10.1038/nri.2016.100

181. Gray M, Botelho RJ. Phagocytosis: hungry, hungry cells. Methods Mol Biol (2017) 1519:1-16. doi:10.1007/978-1-4939-6581-6_1

182. Sanjuan MA, Dillon CP, Tait SW, Moshiach S, Dorsey F, Connell S, et al. Toll-like receptor signalling in macrophages links the autophagy pathway to phagocytosis. Nature (2007) 450:1253-7. doi:10.1038/nature06421

183. Romao S, Münz C. LC3-associated phagocytosis. Autophagy (2014) 10:526-8. doi:10.4161/auto. 27606

184. Ma J, Becker C, Lowell CA, Underhill DM. Dectin-1-triggered recruitment of light chain 3 protein to phagosomes facilitates major histocompatibility complex class II presentation of fungal-derived antigens. J Biol Chem (2012) 287:34149-56. doi:10.1074/jbc.M112.382812

185. Martinez J, Almendinger J, Oberst A, Ness R, Dillon CP, Fitzgerald P, et al. Microtubule-associated protein 1 light chain 3 alpha (LC3)-associated 
phagocytosis is required for the efficient clearance of dead cells. Proc Natl Acad Sci U S A (2011) 108:17396-401. doi:10.1073/pnas.1113421108

186. Henault J, Martinez J, Riggs JM, Tian J, Mehta P, Clarke L, et al. Noncanonical autophagy is required for type I interferon secretion in response to DNA-immune complexes. Immunity (2012) 37:986-97. doi:10.1016/ j.immuni.2012.09.014

187. Martinez J, Malireddi RK, Lu Q, Cunha LD, Pelletier S, Gingras S, et al. Molecular characterization of LC3-associated phagocytosis reveals distinct roles for Rubicon, NOX2 and autophagy proteins. Nat Cell Biol (2015) 17:893-906. doi:10.1038/ncb3192

188. Ueyama T, Nakakita J, Nakamura T, Kobayashi T, Son J, Sakuma M, et al. Cooperation of p40(phox) with p47(phox) for Nox2-based NADPH oxidase activation during $\mathrm{F} c \gamma$ receptor $(\mathrm{F} c \gamma \mathrm{R})$-mediated phagocytosis: mechanism for acquisition of $\mathrm{p} 40$ (phox) phosphatidylinositol 3-phosphate (PI(3) P) binding. J Biol Chem (2011) 286:40693-705. doi:10.1074/jbc.M111. 237289

189. Lam GY, Cemma M, Muise AM, Higgins DE, Brumell JH. Host and bacterial factors that regulate LC3 recruitment to Listeria monocytogenes during the early stages of macrophage infection. Autophagy (2013) 9:985-95. doi:10.4161/auto.24406

190. Martinez J, Cunha LD, Park S, Yang M, Lu Q, Orchard R, et al. Noncanonical autophagy inhibits the autoinflammatory, lupus-like response to dying cells. Nature (2016) 533:115-9. doi:10.1038/nature17950

191. Ma J, Becker C, Reyes C, Underhill DM. Cutting edge: FYCO1 recruitment to dectin-1 phagosomes is accelerated by light chain 3 protein and regulates phagosome maturation and reactive oxygen production. J Immunol (2014) 192:1356-60. doi:10.4049/jimmunol.1302835

192. Delamarre L, Pack M, Chang H, Mellman I, Trombetta ES. Differential lysosomal proteolysis in antigen-presenting cells determines antigen fate. Science (2005) 307:1630-4. doi:10.1126/science.1108003

193. Lee HK, Mattei LM, Steinberg BE, Alberts P, Lee YH, Chervonsky A, et al. In vivo requirement for Atg5 in antigen presentation by dendritic cells. Immunity (2010) 32:227-39. doi:10.1016/j.immuni.2009.12.006

194. Mahad DH, Trapp BD, Lassmann H. Pathological mechanisms in progressive multiple sclerosis. Lancet Neurol (2015) 14:183-93. doi:10.1016/ S1474-4422(14)70256-X

195. Ben-Nun A, Wekerle H, Cohen IR. The rapid isolation of clonable antigen-specific $\mathrm{T}$ lymphocyte lines capable of mediating autoimmune encephalomyelitis. Eur J Immunol (1981) 11:195-9.

196. Ben-Nun A, Wekerle H, Cohen IR. Vaccination against autoimmune encephalomyelitis with T-lymphocyte line cells reactive against myelin basic protein. Nature (1981) 292:60-1.

197. Stromnes IM, Goverman JM. Passive induction of experimental allergic encephalomyelitis. Nat Protoc (2006) 1:1952-60. doi:10.1038/nprot.2006.284

198. Bailey SL, Schreiner B, McMahon EJ, Miller SD. CNS myeloid DCs presenting endogenous myelin peptides 'preferentially' polarize CD4+ TH-17 cells in relapsing EAE. Nat Immunol (2007) 8:172-80. doi:10.1038/ni1430

199. Greter M, Heppner FL, Lemos MP, Odermatt BM, Goebels N, Laufer T, et al. Dendritic cells permit immune invasion of the CNS in an animal model of multiple sclerosis. Nat Med (2005) 11:328-34. doi:10.1038/nm1197

200. Tompkins SM, Padilla J, Dal Canto MC, Ting JP, Van Kaer L, Miller SD. De novo central nervous system processing of myelin antigen is required for the initiation of experimental autoimmune encephalomyelitis. J Immunol (2002) 168:4173-83. doi:10.4049/jimmunol.168.8.4173

201. Hickey WF, Kimura H. Perivascular microglial cells of the CNS are bone marrow-derived and present antigen in vivo. Science (1988) 239:290-2.

202. McMahon EJ, Bailey SL, Castenada CV, Waldner H, Miller SD. Epitope spreading initiates in the CNS in two mouse models of multiple sclerosis. Nat Med (2005) 11:335-9. doi:10.1038/nm1202

203. Huitinga I, van Rooijen N, de Groot CJ, Uitdehaag BM, Dijkstra CD. Suppression of experimental allergic encephalomyelitis in Lewis rats after elimination of macrophages. J Exp Med (1990) 172:1025-33.

204. Becher B, Prat A, Antel JP. Brain-immune connection: immuno-regulatory properties of CNS-resident cells. Glia (2000) 29:293-304. doi:10.1002/ (SICI) 1098-1136(20000215)29:4<293::AID-GLIA1>3.0.CO;2-A

205. Schreiner B, Heppner FL, Becher B. Modeling multiple sclerosis in laboratory animals. Semin Immunopathol (2009) 31:479-95. doi:10.1007/ s00281-009-0181-4
206. Pua HH, Dzhagalov I, Chuck M, Mizushima N, He Y-W. A critical role for the autophagy gene Atg5 in T cell survival and proliferation. J Exp Med (2007) 204:25-31. doi:10.1084/jem.20061303

207. Kovacs JR, Li C, Yang Q, Li G, Garcia IG, Ju S, et al. Autophagy promotes T-cell survival through degradation of proteins of the cell death machinery. Cell Death Differ (2012) 19:144-52. doi:10.1038/cdd.2011.78

208. Kabat AM, Harrison OJ, Riffelmacher T, Moghaddam AE, Pearson CF, Laing A, et al. The autophagy gene Atg16l1 differentially regulates Treg and TH2 cells to control intestinal inflammation. Elife (2016) 5:e12444. doi:10.7554/ eLife. 12444

209. Wei J, Long L, Yang K, Guy C, Shrestha S, Chen Z, et al. Autophagy enforces functional integrity of regulatory $\mathrm{T}$ cells by coupling environmental cues and metabolic homeostasis. Nat Immunol (2016) 17:277-85. doi:10.1038/ni.3365

210. Alirezaei M, Fox HS, Flynn CT, Moore CS, Hebb AL, Frausto RF, et al. Elevated ATG5 expression in autoimmune demyelination and multiple sclerosis. Autophagy (2009) 5:152-8. doi:10.4161/auto.5.2.7348

211. Arsov I, Adebayo A, Kucerova-Levisohn M, Haye J, MacNeil M, Papavasiliou FN, et al. A role for autophagic protein beclin 1 early in lymphocyte development. J Immunol (2011) 186:2201-9. doi:10.4049/jimmunol.1002223

212. Puleston DJ, Zhang H, Powell TJ, Lipina E, Sims S, Panse I, et al. Autophagy is a critical regulator of memory CD8(+) T cell formation. Elife (2014) 3:2516. doi:10.7554/eLife.03706

213. Haq K, McElhaney JE. Immunosenescence: influenza vaccination and the elderly. Curr Opin Immunol (2014) 29:38-42. doi:10.1016/j.coi.2014.03.008

214. Xu X, Araki K, Li S, Han JH, Ye L, Tan WG, et al. Autophagy is essential for effector CD8(+) T cell survival and memory formation. Nat Immunol (2014) 15:1152-61. doi:10.1038/ni.3025

215. Valdor R, Mocholi E, Botbol Y, Guerrero-Ros I, Chandra D, Koga H, et al. Chaperone-mediated autophagy regulates $\mathrm{T}$ cell responses through targeted degradation of negative regulators of T cell activation. Nat Immunol (2014) 15:1046-54. doi:10.1038/ni.3003

216. Fang D, Elly C, Gao B, Fang N, Altman Y, Joazeiro C, et al. Dysregulation of T lymphocyte function in itchy mice: a role for Itch in TH2 differentiation. Nat Immunol (2002) 3:281-7. doi:10.1038/ni763

217. Miller BC, Zhao Z, Stephenson LM, Cadwell K, Pua HH, Lee HK, et al. The autophagy gene ATG5 plays an essential role in B lymphocyte development. Autophagy (2008) 4:309-14. doi:10.4161/auto.5474

218. Hillert J, Olerup O. HLA and MS. Neurology (1993) 43:2426-7.

219. Sospedra M, Martin R. Immunology of multiple sclerosis. Annu Rev Immunol (2005) 23:683-747. doi:10.1146/annurev.immunol.23.021704.115707

220. Nylander A, Hafler DA. Multiple sclerosis. J Clin Invest (2012) 122:1180-8. doi:10.1172/JCI58649

221. Lassmann H, van Horssen J. The molecular basis of neurodegeneration in multiple sclerosis. FEBS Lett (2011) 585:3715-23. doi:10.1016/ j.febslet.2011.08.004

222. Henderson APD, Barnett MH, Parratt JDE, Prineas JW. Multiple sclerosis: distribution of inflammatory cells in newly forming lesions. Ann Neurol (2009) 66:739-53. doi:10.1002/ana.21800

223. Marik C, Felts PA, Bauer J, Lassmann H, Smith KJ. Lesion genesis in a subset of patients with multiple sclerosis: a role for innate immunity? Brain (2007) 130:2800-15. doi:10.1093/brain/awm236

224. Barnett MH, Prineas JW. Relapsing and remitting multiple sclerosis: pathology of the newly forming lesion. Ann Neurol (2004) 55:458-68. doi:10.1002/ ana.20016

225. Paterka M, Siffrin V, Voss JO, Werr J, Hoppmann N, Gollan R, et al. Gatekeeper role of brain antigen-presenting CD11c+ cells in neuroinflammation. $E M B O$ $J$ (2016) 35:89-101. doi:10.15252/embj.201591488

226. Bhattacharya A, Parillon X, Zeng S, Han S, Eissa NT. Deficiency of autophagy in dendritic cells protects against experimental autoimmune encephalomyelitis. J Biol Chem (2014) 289:26525-32. doi:10.1074/jbc.M114.575860

227. Jacobson S, Sekaly RP, Jacobson CL, McFarland HF, Long EO. HLA class II-restricted presentation of cytoplasmic measles virus antigens to cytotoxic T cells. J Virol (1989) 63:1756-62.

228. Nuchtern JG, Biddison WE, Klausner RD. Class II MHC molecules can use the endogenous pathway of antigen presentation. Nature (1990) 343:74-6.

229. Rammensee H, Bachmann J, Emmerich NP, Bachor OA, Stevanović S. SYFPEITHI: database for MHC ligands and peptide motifs. Immunogenetics (1999) 50:213-9. 
230. Nimmerjahn F, Milosevic S, Behrends U, Jaffee EM, Pardoll DM, Bornkamm GW, et al. Major histocompatibility complex class II-restricted presentation of a cytosolic antigen by autophagy. Eur JImmunol (2003) 33:1250-9. doi:10.1002/eji.200323730

231. Brazil MI, Weiss S, Stockinger B. Excessive degradation of intracellular protein in macrophages prevents presentation in the context of major histocompatibility complex class II molecules. Eur J Immunol (1997) 27:1506-14.

232. Dengjel J, Schoor O, Fischer R, Reich M, Kraus M, Müller M, et al. Autophagy promotes MHC class II presentation of peptides from intracellular source proteins. Proc Natl Acad Sci U S A (2005) 102:7922-7. doi:10.1073/ pnas.0501190102

233. Lee HK, Lund JM, Ramanathan B, Mizushima N, Iwasaki A. Autophagydependent viral recognition by plasmacytoid dendritic cells. Science (2007) 315:1398-401. doi:10.1126/science.1136880

234. Delgado MA, Elmaoued RA, Davis AS, Kyei G, Deretic V. Toll-like receptors control autophagy. EMBO J (2008) 27:1110-21. doi:10.1038/emboj. 2008.31

235. Xu Y, Jagannath C, Liu XD, Sharafkhaneh A, Kolodziejska KE, Eissa NT. Tolllike receptor 4 is a sensor for autophagy associated with innate immunity. Immunity (2007) 27:135-44. doi:10.1016/j.immuni.2007.05.022

236. Nedjic J, Aichinger M, Emmerich J, Mizushima N, Klein L. Autophagy in thymic epithelium shapes the T-cell repertoire and is essential for tolerance. Nature (2008) 455:396-400. doi:10.1038/nature07208

237. Prinz M, Garbe F, Schmidt H, Mildner A, Gutcher I, Wolter K, et al. Innate immunity mediated by TLR9 modulates pathogenicity in an animal model of multiple sclerosis. J Clin Invest (2006) 116:456-64. doi:10.1172/ JCI26078

238. Miranda-Hernandez S, Gerlach N, Fletcher JM, Biros E, Mack M, Körner H, et al. Role for MyD88, TLR2 and TLR9 but not TLR1, TLR4 or TLR6 in experimental autoimmune encephalomyelitis. J Immunol (2011) 187:791-804. doi:10.4049/jimmunol.1001992

239. Fischer MT, Wimmer I, Höftberger R, Gerlach S, Haider L, Zrzavy T, et al. Disease-specific molecular events in cortical multiple sclerosis lesions. Brain (2013) 136:1799-815. doi:10.1093/brain/awt110

240. Filippi M, Rocca MA, Martino G, Horsfield MA, Comi G. Magnetization transfer changes in the normal appearing white matter precede the appearance of enhancing lesions in patients with multiple sclerosis. Ann Neurol (1998) 43:809-14.

241. Fazekas F, Ropele S, Enzinger C, Seifert T, Strasser-Fuchs S. Quantitative magnetization transfer imaging of pre-lesional white-matter changes in multiple sclerosis. Mult Scler (2002) 8:479-84. doi:10.1191/1352458502ms860oa

242. Huynh JL, Garg P, Thin TH, Yoo S, Dutta R, Trapp BD, et al. Epigenome-wide differences in pathology-free regions of multiple sclerosis-affected brains. Nat Neurosci (2014) 17:121-30. doi:10.1038/nn.3588

243. Traka M, Podojil JR, McCarthy DP, Miller SD, Popko B. Oligodendrocyte death results in immune-mediated CNS demyelination. Nat Neurosci (2016) 19:65-74. doi:10.1038/nn.4193

244. Stys PK, Zamponi GW, van Minnen J, Geurts JJG. Will the real multiple sclerosis please stand up? Nat Rev Neurosci (2012) 13:507-14. doi:10.1038/ nrn3275

245. Fischer MT, Sharma R, Lim JL, Haider L, Frischer JM, Drexhage J, et al. NADPH oxidase expression in active multiple sclerosis lesions in relation to oxidative tissue damage and mitochondrial injury. Brain (2012) 135:886-99. doi:10.1093/brain/aws012

246. Lam GY, Huang J, Brumell JH. The many roles of NOX2 NADPH oxidasederived ROS in immunity. Semin Immunopathol (2010) 32:415-30. doi:10.1007/s00281-010-0221-0

247. Petry A, Weitnauer M, Görlach A. Receptor activation of NADPH oxidases. Antioxid Redox Signal (2010) 13:467-87. doi:10.1089/ars.2009.3026

248. Savina A, Jancic C, Hugues S, Guermonprez P, Vargas P, Moura IC, et al. NOX2 controls phagosomal $\mathrm{pH}$ to regulate antigen processing during crosspresentation by dendritic cells. Cell (2006) 126:205-18. doi:10.1016/j. cell.2006.05.035

249. Rybicka JM, Balce DR, Chaudhuri S, Allan ERO, Yates RM. Phagosomal proteolysis in dendritic cells is modulated by NADPH oxidase in a pH-independent manner. EMBO J (2012) 31:932-44. doi:10.1038/emboj.2011.440

250. Allan ER, Tailor P, Balce DR, Pirzadeh P, McKenna NT, Renaux B, et al. NADPH oxidase modifies patterns of MHC class II-restricted epitopic repertoires through redox control of antigen processing. J Immunol (2014) 192:4989-5001. doi:10.4049/jimmunol.1302896

251. Mahad D, Ziabreva I, Lassmann H, Turnbull D. Mitochondrial defects in acute multiple sclerosis lesions. Brain (2008) 131:1722-35. doi:10.1093/ brain/awn105

252. Campbell GR, Ohno N, Turnbull DM, Mahad DJ. Mitochondrial changes within axons in multiple sclerosis: an update. Curr Opin Neurol (2012) 25:221-30. doi:10.1097/WCO.0b013e3283533a25

253. Trapp BD, Stys PK. Virtual hypoxia and chronic necrosis of demyelinated axons in multiple sclerosis. Lancet Neurol (2009) 8:280-91. doi:10.1016/ S1474-4422(09)70043-2

254. Guo H, Wei J, Kuo PC. Nitric oxide inhibits expression of cytochrome B in endotoxin-stimulated murine macrophages. Biochem Biophys Res Commun (2001) 289:993-7. doi:10.1006/bbrc.2001.6107

255. Wei J, Guo H, Kuo PC. Endotoxin-stimulated nitric oxide production inhibits expression of cytochrome c oxidase in ANA-1 murine macrophages. J Immunol (2002) 168:4721-7. doi:10.4049/jimmunol.168.9.4721

256. Larsson N-G. Somatic mitochondrial DNA mutations in mammalian aging. Annu Rev Biochem (2010) 79:683-706. doi:10.1146/annurev-biochem060408-093701

257. Bolaños JP, Almeida A, Stewart V, Peuchen S, Land JM, Clark JB, et al. Nitric oxide-mediated mitochondrial damage in the brain: mechanisms and implications for neurodegenerative diseases. J Neurochem (1997) 68:2227-40. doi:10.1046/j.1471-4159.1997.68062227.x

258. Cross AH, Manning PT, Keeling RM, Schmidt RE, Misko TP. Peroxynitrite formation within the central nervous system in active multiple sclerosis. J Neuroimmunol (1998) 88:45-56. doi:10.1016/S0165-5728(98) 00078-2

259. Liu JS, Zhao ML, Brosnan CF, Lee SC. Expression of inducible nitric oxide synthase and nitrotyrosine in multiple sclerosis lesions. Am J Pathol (2001) 158:2057-66. doi:10.1016/S0002-9440(10)64677-9

260. Zeis T, Probst A, Steck AJ, Stadelmann C, Brück W, Schaeren-Wiemers N. Molecular changes in white matter adjacent to an active demyelinating lesion in early multiple sclerosis. Brain Pathol (2009) 19:459-66. doi:10.1111/j.1750-3639.2008.00231.x

261. Cavaliere F, Urra O, Alberdi E, Matute C. Oligodendrocyte differentiation from adult multipotent stem cells is modulated by glutamate. Cell Death Dis (2012) 3:e268. doi:10.1038/cddis.2011.144

262. Accetta R, Damiano S, Morano A, Mondola P, Paternò R, Avvedimento EV, et al. Reactive oxygen species derived from NOX3 and NOX5 drive differentiation of human oligodendrocytes. Front Cell Neurosci (2016) 10:146. doi:10.3389/fncel.2016.00146

263. Twig G, Hyde B, Shirihai OS. Mitochondrial fusion, fission and autophagy as a quality control axis: the bioenergetic view. Biochim Biophys Acta (2008) 1777:1092-7. doi:10.1016/j.bbabio.2008.05.001

264. Harris H, Rubinsztein DC. Control of autophagy as a therapy for neurodegenerative disease. Nat Rev Neurol (2011) 8:108-17. doi:10.1038/ nrneurol.2011.200

265. Rolland SG, Motori E, Memar N, Hench J, Frank S, Winklhofer KF, et al. Impaired complex IV activity in response to loss of LRPPRC function can be compensated by mitochondrial hyperfusion. Proc Natl Acad Sci U S A (2013) 110:E2967-76. doi:10.1073/pnas.1303872110

266. Witte ME, Bø L, Rodenburg RJ, Belien JA, Musters R, Hazes T, et al. Enhanced number and activity of mitochondria in multiple sclerosis lesions. J Pathol (2009) 219:193-204. doi:10.1002/path.2582

267. Mahad DJ, Ziabreva I, Campbell G, Lax N, White K, Hanson PS, et al. Mitochondrial changes within axons in multiple sclerosis. Brain (2009) 132:1161-74. doi:10.1093/brain/awp046

268. Cai Q, Zakaria HM, Simone A, Sheng Z-H. Spatial parkin translocation and degradation of damaged mitochondria via mitophagy in live cortical neurons. Curr Biol (2012) 22:545-52. doi:10.1016/j.cub.2012.02.005

269. Sheng Z-H. Mitochondrial trafficking and anchoring in neurons: new insight and implications. JCell Biol (2014) 204:1087-98. doi:10.1083/jcb. 201312123

270. Ohno N, Chiang H, Mahad DJ, Kidd GJ, Liu L, Ransohoff RM, et al. Mitochondrial immobilization mediated by syntaphilin facilitates survival of demyelinated axons. Proc Natl Acad Sci U S A (2014) 111:9953-8. doi:10.1073/pnas.1401155111 
271. Yamamoto A, Yue Z. Autophagy and its normal and pathogenic states in the brain. Annu Rev Neurosci (2014) 37:55-78. doi:10.1146/ annurev-neuro-071013-014149

272. Campbell GR, Ziabreva I, Reeve AK, Krishnan KJ, Reynolds R, Howell O, et al. Mitochondrial DNA deletions and neurodegeneration in multiple sclerosis. Ann Neurol (2011) 69:481-92. doi:10.1002/ana.22109

273. Gao L, Laude K, Cai H. Mitochondrial pathophysiology, reactive oxygen species, and cardiovascular diseases. Vet Clin North Am Small Anim Pract (2008) 38:137-55, vi. doi:10.1016/j.cvsm.2007.10.004

274. Lizama-Manibusan B, McLaughlin B. Redox modification of proteins as essential mediators of CNS autophagy and mitophagy. FEBS Lett (2013) 587:2291-8. doi:10.1016/j.febslet.2013.06.007

275. Scherz-Shouval R, Shvets E, Fass E, Shorer H, Gil L, Elazar Z. Reactive oxygen species are essential for autophagy and specifically regulate the activity of Atg4. EMBO J (2007) 26:1749-60. doi:10.1038/sj.emboj.7601623

276. Lee IH, Cao L, Mostoslavsky R, Lombard DB, Liu J, Bruns NE, et al. A role for the NAD-dependent deacetylase Sirt1 in the regulation of autophagy. Proc Natl Acad Sci U S A (2008) 105:3374-9. doi:10.1073/pnas.0712145105

277. van Horssen J, Schreibelt G, Drexhage J, Hazes T, Dijkstra CD, van der Valk $\mathrm{P}$, et al. Severe oxidative damage in multiple sclerosis lesions coincides with enhanced antioxidant enzyme expression. Free Radic Biol Med (2008) 45:1729-37. doi:10.1016/j.freeradbiomed.2008.09.023

278. Juurlink BH, Thorburne SK, Hertz L. Peroxide-scavenging deficit underlies oligodendrocyte susceptibility to oxidative stress. Glia (1998) 22:371-8.

279. Barja G. Updating the mitochondrial free radical theory of aging: an integrated view, key aspects, and confounding concepts. Antioxid Redox Signal (2013) 19:1420-45. doi:10.1089/ars.2012.5148
280. Haider L, Fischer MT, Frischer JM, Bauer J, Höftberger R, Botond G, et al. Oxidative damage in multiple sclerosis lesions. Brain (2011) 134:1914-24. doi:10.1093/brain/awr128

281. Harrison DE, Strong R, Sharp ZD, Nelson JF, Astle CM, Flurkey K, et al. Rapamycin fed late in life extends lifespan in genetically heterogeneous mice. Nature (2009) 460:392-5. doi:10.1038/nature08221

282. Martínez-Cisuelo V, Gómez J, García-Junceda I, Naudí A, Cabré R, Mota-Martorell N, et al. Rapamycin reverses age-related increases in mitochondrial ROS production at complex I, oxidative stress, accumulation of mtDNA fragments inside nuclear DNA, and lipofuscin level, and increases autophagy, in the liver of middle-aged mice. Exp Gerontol (2016) 83:130-8. doi:10.1016/j.exger.2016.08.002

283. Wang B, Cai Z, Tao K, Zeng W, Lu F, Yang R, et al. Essential control of mitochondrial morphology and function by chaperone-mediated autophagy through degradation of PARK7. Autophagy (2016) 12:1215-28. doi:10.1080/15548627.2016.1179401

Conflict of Interest Statement: The authors declare that the research was conducted in the absence of any commercial or financial relationships that could be construed as a potential conflict of interest.

Copyright (C) 2017 Keller and Lünemann. This is an open-access article distributed under the terms of the Creative Commons Attribution License (CC BY). The use, distribution or reproduction in other forums is permitted, provided the original author(s) or licensor are credited and that the original publication in this journal is cited, in accordance with accepted academic practice. No use, distribution or reproduction is permitted which does not comply with these terms. 